\title{
Preparation and Use of Aqueous Solutions Magnetic Chitosan / Nanocellulose Aerogels for the Sorption of Reactive Black 5
}

\author{
Manal M. El-Zawahry $\left.{ }^{1} \mathbb{(}\right)$, Ahmed G. Hassabo ${ }^{2, *}{ }^{\mathbb{D}}$, Fatma Abdelghaffar ${ }^{1(\mathbb{D})}$ \\ Rehab A. Abdelghaffar ${ }^{1}$ (D), Osama A. Hakeim ${ }^{3}$ (D) \\ 1 National Research Centre (Scopus affiliation ID 60014618), Textile Industries Research Division (TIRD), Dyeing, Printing \\ and Textile Intermediate Department (DPTID), 33 El-Behouth St. (former El-Tahrir str.), Dokki, P.O. 12622, Giza, Egypt \\ 2 National Research Centre (NRC, Scopus affiliation ID 60014618), Textile Industries Research Division (TIRD), Pre- \\ treatment and Finishing of Cellulose-based Textiles Department (PFCTD), El-Behouth St. (former El-Tahrir str.), Dokki, \\ P.O. 12622, Giza, Egypt \\ * Correspondence: aga.hassabo@hotmail.com;
}

Scopus Author ID: 55909104700

Received: 4.12.2020; Revised: 28.12.2020; Accepted: 2.01.2021; Published: 4.01.2021

\begin{abstract}
For the disposal of Reactive Black 5 from aqueous solutions, the hydrophilic, magnetic, and extremely porous aerogels derived from rice straw waste have been synthesized. The first rice straw was made of nanocellulose crystals. Instant gelation and cross-linking processes were then used to prepare magnetic chitosan/nanocellulose aerogel beads. The aerogels have been distinguished by different technology, namely FT-IR, TEM, EDX, DLS and VSM. Results revealed the effective preparation of magnet chitosan / nanocellulose aerogels. Reactive Black 5 can be removed in acidic media and at a time of touch of 30 minutes. The aerogels absorbed color should be used as a dye color in textile printing. Secondary emission can be avoided. The future use of magnet chitosan / nanocellulose aerogels as an absorbent color can be based on its simple environment, using minimum precursor effort.
\end{abstract}

Keywords: magnetic chitosan; nanocellulose; Reactive Black 5; biopolymer material; adsorption isotherm; kinetics.

(C) 2020 by the authors. This article is an open-access article distributed under the terms and conditions of the Creative Commons Attribution (CC BY) license (https://creativecommons.org/licenses/by/4.0/).

\section{Introduction}

Significant pollutants in wastewater have arisen from many industries such as printing, textiles, paper, plastics, leather, cosmetics, etc. [1-3]. Textile industries are overly the primary pollutants concern based on the amounts of discharge and effluent composition. Generally, the dyeing process releases approximately from 10 to $15 \%$ of textile dyes as dye effluent in ecology. In particular, reactive and direct dyes discharge, nearly about $30 \%$ in the final effluents [4]. Furthermore, conventional approaches for removing dyes from wastewater revealed various drawbacks. The dyes are extremely stable, resist degradation by light and other exposures [5]. Accordingly, conventional wastewater treatments remain ineffective [6].

Hence, the search for low-cost, renewable, locally available materials as biosorbent for removing dyeing colors, such as chitosan, cellulose, and Rhizopus oryzae is the subject of studying dye removal [7-9]. 
Cellulose is one of the most used materials in many fields because it is an inexhaustible, natural, sustainable, and biodegradable material in the world. It drew nearer as one of the potential assets for manufacturing green adsorbents. It diminished their accumulation of conceivable outcomes with different materials such as silicon or nanoparticles [10-20].

It has been assumed that cellulosic nanomaterial adsorbents, profiting by the high explicit surface area for interactions with other objective molecules, have the highest adsorption capacity among the other conventional adsorbents such as chitin, chitosan and so on [21].

Rice straw is one of the most well-known sources of biomass accessible on the planet. It is a cheap and sustainable source, which led to the continuous production of high-quality natural cellulose fibers [22]. Many analysts have been concentrating on the effectiveness of adjusted rice straw as an adsorbent for toxic heavy metal and dye removal using rice straw [23].

Meanwhile, chitosan is a biodegradable and inexhaustible biopolymer acquired from chitin's deacetylation, which is the second most numerous polysaccharides besides cellulose [24]. The presence of amino and hydroxyl groups in chitosan-based adsorbents causes a good adsorption process with excellent kinetic behavior and sustainability, making these absorbents type one of the most encouraging functional materials for natural remediation [25-29].

Aerogels have recently been fabricated for dye adsorption due to their intelligent properties, such as high porosity, large surface area, ultralow thermal conductivity, ultra-light densities, and good adsorption capacity. Aerogels are commonly prepared by drying hydrogels to remove liquid without collapsing the porous in its network structure [30-32]. The crosslinked inside aerogel structure provides the highest surface area per gram $\left(1000 \mathrm{~m}^{2} / \mathrm{g}\right)$ comparing to other known material [33].

Cellulosic aerogels are known as one of the most important, environmentally ecofriendly materials based on cellulose-containing materials [34]. They show the promising capability of absorbents, as they are inexhaustible, accessible richly, cheap, highly flexible, and excellent mechanical properties [30].

Magnetism is an individual physical property that can be exploited in water purification by influencing the pollutants' physical properties in water. [35] Magnetic chitosan composites are materials that exhibit great sorption behavior towards different toxic contaminants in an aqueous solution. Besides, these composites have a fast adsorption rate with high activity, effective in removing many pollutants, and easy to recover-reactivated and reuse again [3638].

In this investigation, novel magnetic chitosan/nanocellulose aerogel beads were prepared through gelation and cross-linking methods to be used for absorption of Reactive Black 5 (RB5, anionic nature) from dye/water mixture. Chitosan has been selected as it has large amounts of cationic amino groups that facilitate the fast adsorption of anionic dyes.

The dye removal from its aqueous solution was studied as a function of contact time, $\mathrm{pH}$, and dye concentration. In these hybrids, magnetic materials were chosen to easily recover from water by using an external magnet and could be reused with the adsorbed colors as a pigment in textile printing using the pigment printing technique. This endeavor makes them suited for applications concerning economic feasibility and potential utility and avoids secondary pollution. The choice of agricultural waste is usually burned or used as a low-value product as an alternative adsorbent. Solving the problem of generating toxic sludge would be our most significant challenge in this study. 


\section{Materials and Methods}

\subsection{Materials.}

Rice straw (RS) (purchased from Racta Co. for paper manufacture, Alexandria, Egypt) was washed with water, dried in an oven at $60^{\circ} \mathrm{C}$ for $6 \mathrm{~h}$. Iron (II, III) oxide nano-powder (< $50 \mathrm{~nm}, \geq 98 \%$ ) was purchased from Merck Co. High molecular weight chitosan (Mwt $=800000$ $\mathrm{g} / \mathrm{mol}, \mathrm{N} \%=6.31$ ) and C.I. Reactive Black 5 (anionic RB5; Mwt $=991.82 \mathrm{~g} / \mathrm{mol}, K_{\max }=597$ $\mathrm{nm})$ ) were supplied by Sigma-Aldrich. Synthetic thickener Alcoprint (PTP), Imperon Binder (MTB; density ca. $1.03 \mathrm{~g} / \mathrm{cm}^{3}$ and viscosity 35-70 MPas), and acrylate-based copolymer dispersion were supplied as a commercial product and used in pigment printing. Other chemicals or reagents were used in laboratory grade.

\subsection{Methods.}

\subsubsection{Preparation of nanocellulose crystals from rice straw.}

2.2.1.1. Isolation of cellulosic materials from rice straw wastes.

Rice straw stem was washed with water as small segments several times to remove dirt, soil, dust, and any soluble substances, then dried in air. The dried rice straw was ground well with a mill to a fine powder. To remove wax, pigments, and oils, $30 \mathrm{~g}$ powder was purified with toluene/ethanol mixture $(2: 1 ; \mathrm{v} / \mathrm{v})$ for $20 \mathrm{~h}$ in the Soxhlet system and then dried at room temperature overnight. The dried powder was acidified with $\mathrm{NaClO}_{2}(1.4 \%, \mathrm{pH} 3-4)$ at $70^{\circ} \mathrm{C}$ for $5 \mathrm{~h}$ to remove lignin. Then it was washed with distilled water until neutral. Hemicellulose and silica were removed from the resulted powder through treatment with $600 \mathrm{ml} \mathrm{KOH} 5 \%$ at room temperature for $24 \mathrm{~h}$, the temperature was raised to $90^{\circ} \mathrm{C}$ and kept for $2 \mathrm{~h}$. The cellulose powder was then washed with deionized water and dried at room temperature to get the final powder with a $35 \%$ yield [39].

\subsubsection{Preparation of nanocellulose crystals.}

Prepared cellulose powder was hydrolyzed with sulfuric acid (65\%); each $1 \mathrm{~g}$ cellulose powder was hydrolyzed with $8.75 \mathrm{ml}$ acid $(1: 8.75 \mathrm{~g} / \mathrm{v})$; at $45^{\circ} \mathrm{C}$ for $30 \mathrm{~min}$ under continuous stirring. The acid hydrolysis process was stopped by placing the flask in an ice bath and adding 10 -fold ice water and then filtrated. $50 \mathrm{ml}$ water was added to the resulting nanocellulose crystals (NC) then centrifuged at $4000 \mathrm{rpm}$ for $30 \mathrm{~min}$. the powder was washed with deionized water until obtaining a neutral $\mathrm{pH}$ [39].

2.2.2. Preparation of magnetic chitosan/nanocellulose aerogels beads by quick precipitated method (m-CS/NC ABs-P).

The magnetic chitosan/nanocellulose aerogels with the weight ratio of acidified chitosan (2\% W/V, initial concentration $20 \mathrm{~g} / \mathrm{l}): \mathrm{NC}: \mathrm{Fe}_{3} \mathrm{O}_{4}$ nanoparticles with 1: 2: 0.5 ratios were synthesized by a gelation method as follow: $2 \%$ chitosan (w/v) in acetic acid solution (1 $\%$ ) was prepared. $\mathrm{NC}$ was added $(40 \mathrm{~g} / \mathrm{l})$ to the acidified chitosan solution with vigorous stirring using a homogenizer stirrer for $30 \mathrm{~min}$. Then, $\mathrm{Fe}_{3} \mathrm{O}_{4} \mathrm{NPs}$ were added gradually into the mixture under continuous stirring. Stirring was continued for $1 \mathrm{~h}$ at room temperature to produce a composite gel solution. The resulting mixed black gel was filled up in a syringe and dropped 
into $0.1 \mathrm{~N} \mathrm{NaOH}$ solution forming the hydrogel instantaneously. The magnetic hydrogel was collected from the solution using a magnet and then washed with distilled water. Finally, the aerogels with a small density and high porosity were prepared by vacuum freeze-drying for 12 $\mathrm{h}[8]$.

2.2.3. Preparation of magnetic chitosan/nanocellulose aerogels by cross-linking method ( $\mathrm{m}$ CS/NC ABs-C).

As previously prepared in the precipitation method, $\mathrm{Fe}_{3} \mathrm{O}_{4} \mathrm{NPs}$ would be added to the acidified chitosan suspension with a high, stirring rate using a homogenizer stirrer for $30 \mathrm{~min}$. In this method, the nano-cellulose gel was added into the mixture under continuous stirring for $1 \mathrm{~h}$ till the black suspension was formed. Finally, $1 \mathrm{ml}$ of glutaraldehyde solution would be added under stirring until a gelatinous product was obtained. Then, the black gel (m-CS/NC ABs-C) was washed with distilled water and dried by freeze-drying for $12 \mathrm{~h} \mathrm{[40].}$

\subsection{Characterization of magnetic chitosan/nanocellulose aerogel.}

The functional groups of NC and the two aerogels were investigated using the Fourier Transform Infrared spectroscopy (FT-IR). FT-IR was recorded on JASCO FT-IR spectrometer (ATR), Japan. The morphology was examined by Scanning Electron Microscope (SEM) Model Philips XL 30 with an EDX unit attached. Transmission Electron Microscopy (TEM), Model EM-1230; Jeol, Germany was used to measure particle size diameter and dimension of the aerogel nanoparticles. Zeta potential was measured on a Zetasizer Nano ZS (Malvern Instruments, Malvern, UK). The swelling degree was determined by calculating the average of triplicate experiments using the following equation [4,41-43]:

$$
\text { Swelling \% }=\frac{W_{s}-W_{d}}{W_{d}} \times 100
$$

Where, $\mathrm{W}_{\mathrm{d}}=$ weight of aerogel; Ws= weight of swollen aerogel.

\subsection{Determination of Surface Area and Pore Diameter.}

Brunauer-Emmett-Teller (BET) theory was used to explain the gels surface area, pore size diameter, and the physical adsorption of gas molecules on a solid surface [44]. The nitrogen adsorption-desorption isotherm data using Bel Sorb Max device (Japan) can be expressed as follows:

$$
v=\frac{v_{m} c p}{\left(p_{o}-p\right)\left[1+(c-1)\left(\frac{p}{p_{o}}\right)\right]}
$$

where, $\mathrm{v}$ is the adsorbed gas volume, $\mathrm{v}_{\mathrm{m}}$ is the adsorbed monolayer volume, $\mathrm{p}$ is the equilibrium gas pressure, $\mathrm{p}_{\mathrm{o}}$ is the saturation pressure and $\mathrm{c}$ is the BET constant. The rearrangement of the above equation to a linear form can be expressed as follows:

$$
\frac{1}{v\left[\left(\frac{p}{p_{o}}\right)-1\right]}=\frac{c-1}{v_{m} c}\left(\frac{p}{p_{o}}\right)+\frac{1}{v_{m} c}
$$

Plotting of the previous equation between $\left(\frac{p}{p_{o}}\right)$ and $\frac{1}{v\left[\left(\frac{p}{p_{o}}\right)-1\right]}$. The intercept and slope function can be used to determine the constants $c=\frac{\text { slope }}{\text { intercept }}+1$ and $v_{m}=\frac{1}{\text { slope+intercept }}$. The specific surface area (S, surface area per unit mass) can be calculated by the equation: 


$$
S=\frac{v_{m} N A}{22400 \times m}
$$

where $\mathrm{N}$ is Avogadro's number, $\mathrm{A}$ is the cross-sectional surface area of a single adsorbed gas molecule; $\mathrm{m}$ is the mass of nanomaterials used in the measurement, and Standard Temperature and Pressure (STP) represents as 22400 . The standard temperature used is 273 Kelvin or $0{ }^{\circ} \mathrm{C}$, and the standard pressure is 1 atmosphere $(760 \mathrm{~mm} \mathrm{Hg})$. At STP, one mole of any gas occupies a volume of 22.4 litres $(22400 \mathrm{ml})$. The surface area (area/mass; $\mathrm{m}^{2} / \mathrm{g}$ ) can be converted to a volume-specific surface area via multiplying by the material density.

According to Wheeler's equation, a change in pore volume or surface area can offset the pore diameter.

$$
d(n m)=\frac{4000 \times V(m l / g)}{S\left(m^{2} / g\right)}
$$

where $\mathrm{d}$ is the mean pore diameter, $\mathrm{V}$ is the total pore volume, and $\mathrm{S}$ is the surface area.

\subsection{Color removal studies.}

The batch systems were performed by dissolving a constant concentration of RB5 (25$300 \mathrm{mg} / \mathrm{l})$ in distilled water using Erlenmeyer flasks and various amounts of the adsorbent $(0.5$ $-20 \mathrm{~g} / \mathrm{l})$. The $\mathrm{pH}$ of the solutions was studied $\mathrm{pH}(1-10)$. The nanocellulose aerogels were then removed by a magnet, and the color removal efficiency of the RB5 was measured using a UV/visible-spectrophotometer at $\lambda_{\max }=597 \mathrm{~nm}$ and determined according to the following equation $[23,45]$ :

$$
\text { RB5 removal efficiency }(\%)=\frac{\mathrm{A}_{0}-\mathrm{A}_{1}}{\mathrm{~A}_{0}} \times 100
$$

where $A_{0}$ and $A_{1}$ are the dyebath absorbances before and after dye adsorption, respectively.

\subsection{Color measurements.}

The color strength values (K/S) of the printed fabrics were measured with a Hunter Lab Ultra ScanPRO USA, 2007 according to a standard method at the wavelength of the maximum absorbance. The K/S values were assessed by applying the Kubelka -Munk equation as follows:

$$
\mathrm{K} / \mathrm{S}=\frac{(1-R)^{2}}{\left(1-R_{O}\right)^{2}}-\frac{2 R}{2 R_{O}}
$$

where $\mathrm{K}$ is the absorption coefficient, $\mathrm{S}$ is the scattering coefficient, $\mathrm{R}_{\mathrm{o}}$ and $\mathrm{R}$ are the reflectance of the uncolored (white) sample and colored sample, respectively [46-50].

\subsection{Reusability of $m-C S / N C A B s$ with the adsorbed RB5 as a pigment color in textile printing.}

m-CS/NC ABs were immediately released with the adsorbed RB5 from its solutions using an external magnet. They were then dried at room temperature for a couple of days in a vacuum oven. The dried samples were crushed and milled until the attainment of fine colored powders. The m-CS/NC ABs colored powders were used for printing silk, wool, and cotton using the pigment printing technique. The paste formulations were prepared by adding the synthetic thickener (PTP, $25 \mathrm{~g} / \mathrm{kg}$ ) to water under stirring, then $100 \mathrm{~g} / \mathrm{kg}$ binder (MTB) and 5 $\mathrm{g} / \mathrm{kg}$ diammonium phosphate were added. Finally, m-CS/NC ABs $(25 \mathrm{~g} / \mathrm{kg})$ colored powders were added to the stock thickening. The flat silkscreen technique was used to apply to transfer 
the paste to the fabrics. Printed fabrics were dried and cured at $150^{\circ} \mathrm{C}$ for $5 \mathrm{~min}$. Printed samples were washed with an aqueous solution containing $(2 \mathrm{~g} / \mathrm{l})$ of non-ionic detergent at $60^{\circ} \mathrm{C}$ for 15 min. dried at $80^{\circ} \mathrm{C}$ for $3 \min$ [51].

\subsection{Adsorption and isothermal studies.}

Adsorption isotherms experiments were performed for the NC and both aerogels [4,52]. Varying quantities of nanocellulose-based aerogels $(0.5-20 \mathrm{~g} / \mathrm{l})$ were applied to Erlenmeyer flasks containing $100 \mathrm{ml}$ of an RB5 solution $25-300 \mathrm{mg} / \mathrm{l}$.

The solutions $\mathrm{pH}$ were balanced using acetic acid to $\mathrm{pH} 3-4$. The flasks were then well shaken for $3 \mathrm{~h}$ at room temperature until equilibrium was reached. Upon magnetic separation of nanocellulose aerogels, a UV / visible spectrophotometer (UV-1601 Shimadzu, Japan) was used to measure the concentration of the RB5 in the solution at $597 \mathrm{~nm}$.

For kinetic tests, sampling was performed at different time intervals (10-240 min) after the procedure, $5 \mathrm{ml}$ of the residual RB5 concentration was measured using a UV - Vis spectrophotometer, and the amount of RB5 adsorbed by nanocellulose aerogel composites were determined in triplicate experiments to check the results.

The results were analyzed in three separate kinetic models: I pseudo-first-order, ii) pseudo-second-order model, and Cegarra - Puente equation [4,53,54].

The formula of the pseudo-first-order value is shown below:

$\frac{d q}{d t}=k_{1}\left(q_{e}-q_{t}\right)^{n} \rightarrow \ln \left(q_{e}-q_{t}\right)=\ln \left(q_{e}\right)-k_{e 1} t$ for $\mathrm{n}=1$ (first-order reaction)

where $q_{t}$ is the amount of dye adsorbed $(\mathrm{mg} / \mathrm{g})$ at time $t, q_{e}$ is the maximum adsorption capacity $(\mathrm{mg} / \mathrm{g}), k$ is the rate constant $(\mathrm{min})$, and $n$ is the reaction order.

The formula of the pseudo-second-order value is shown below:

$$
\frac{1}{q_{t}}=\left(\frac{1}{k_{2} q_{e}^{2}}\right)\left(\frac{1}{t}\right)+\frac{1}{q_{e}}
$$

where, $q_{t}$ is the amount of dye adsorbed $(\mathrm{mg} / \mathrm{g})$ at time $t, q_{e}$ is the maximum adsorption capacity $(\mathrm{mg} / \mathrm{g}), k_{2}$ is the second-order rate constant ( $\left.\mathrm{min}\right)$.

The formula of Cegarra-Puente is usually expressed as:

$$
\ln \left(1-\frac{C_{t}}{C_{\infty}}\right)=-k t
$$

where, the concentration of dye after time $\mathrm{t}$ is $\mathrm{c}_{\mathrm{t}}, \mathrm{c}_{\infty}$ is the equilibrium concentration of dye (in our case after $180 \mathrm{~min}$ ), and $\mathrm{k}$ is the constant of Cegarra - Puente.

Use a UV-vis spectrophotometer. The total sorption capacity is measured at different initial dye concentrations. The maximum sorption capacity values are represented as adsorbed dye concentration $(\mathrm{mg} / \mathrm{g})$ vs. different initial dye concentrations.

During this analysis, isothermal models for Langmuir, Freundlich, and BET adsorption were used [55,56]. The isotherm of Langmuir is widely used for describing single-solute systems [57]. The following formula is given to the Langmuir isotherm:

$$
q_{e}=\frac{q_{m} C_{e} K_{L}}{1+C_{e} K_{L}} \quad====>\frac{1}{q_{e}}=\frac{1}{q_{m}}+\left(\frac{1}{q_{m} K_{L}}\right)\left(\frac{1}{C_{e}}\right)
$$

where, $\mathrm{q}_{\mathrm{e}}$ is the concentration at dye equilibrium on nanocellulose-based aerogel composite $(\mathrm{mg} / \mathrm{g}), \mathrm{q}_{\mathrm{m}}$ is the concentration of equilibrium dye in solution $(\mathrm{mg} / \mathrm{l}), \mathrm{q}_{\mathrm{m}}$ is the maximum capacity of nanocellulose-based aerogel composite $(\mathrm{mg} / \mathrm{g})$, and $\mathrm{K}_{\mathrm{L}}$ is the constant of Langmuir 
$\left(\mathrm{L} / \mathrm{mg}\right.$ ) adsorption. The linearization of the $1 / \mathrm{q}_{\mathrm{e}}$ versus $1 / \mathrm{C}_{\mathrm{e}}$ Langmuir isotherm plotting gives a straight line with a $1 / \mathrm{q}_{\mathrm{e}} \mathrm{K}_{\mathrm{L}}$ slope and a $1 / \mathrm{q}_{\mathrm{m}}$ intercept.

For describing heterogeneous structures, Freundlich isotherm is fine. [57] The isothermic formula of Freundlich is as follows:

$$
q_{e}=q_{e} C_{e}^{1 / n}====>\ln \left(q_{e}\right)=\ln \left(K_{F}\right)+\frac{1}{n} \ln \left(C_{e}\right)
$$

where, $\mathrm{q}_{\mathrm{e}}$ is the concentration of equilibrium dye on the nanocellulose-based composite surface $(\mathrm{mg} / \mathrm{g}), \mathrm{C}_{\mathrm{e}}$ is the concentration of equilibrium dye in solution $(\mathrm{mg} / \mathrm{l}), \mathrm{K}_{\mathrm{F}}$ is the Freundlich adsorption constant $(\mathrm{L} / \mathrm{mg})$, and $\mathrm{n}$ is the heterogeneity variable.

Brunauer-Emmett-Teller (BET) isotherm model [58] This model's liner shape is written as follows:

$$
C_{f}=\frac{\left(K_{b}-1\right)\left(K_{b} C_{\max } C_{S}\right)+K_{b} C_{\max } C_{i}}{\left(C_{i}-C_{S}\right)\left(K_{b}-1\right)} \quad===>\quad \frac{C_{S}}{\left(C_{i}-C_{S}\right) C_{f}}=\frac{1}{K_{b} C_{\max }}+\left(\frac{K_{b}-1}{K_{b} C_{\max }}\right)\left(\frac{C_{s}}{C_{i}}\right)
$$

where $\mathrm{C}_{\mathrm{f}}$ is the dye concentration adsorbed on the composite nanocellulose-based aerogel layer, $\mathrm{C}_{\mathrm{s}}$ is the dye concentration throughout the treatment pool, $\mathrm{C}_{\max }$ is the total adsorption strength of the composite nanocellulose-based aerogel $(\mathrm{mg} / \mathrm{g}), \mathrm{C}_{\mathrm{i}}$ is the dye saturation concentration $(\mathrm{mg} / \mathrm{l})$ and $\mathrm{K}_{\mathrm{b}}$ is the constant definition of the energy interaction with the composite nanocellulose-based aerogel. Plotting $\left(C_{s} /\left(C_{i}-C_{s}\right) C_{f}\right)$ versus $\left(C_{s} / C_{i}\right)$ gives the gradient of $\left(\left(K_{b}-1\right) /\left(K_{b} \times C_{\max }\right)\right)$ and the intercept of $\left(1 /\left(K_{b}-1\right)\right)$ a straight line.

\subsection{Error analysis.}

Because of the innate predisposition arising from the linearization of the isothermal and dynamic models, four different non-linear relapse bowl error functions were used as suitable criteria $[4,13,42-44]$.

The root means square error (RMSE) has been utilized by various analysts in the field to test the sufficiency and precision of the model fit with the exploratory information.

Different field analysts used the root mean square error (RMSE) to check the sufficiency and reliability of the model fit with the exploratory information:

$$
\text { RMSE }=\sqrt{\frac{1}{n-2} \sum_{i=1}^{n}\left(q_{i}-q_{i . e}\right)^{2}}
$$

where, $q_{i}$ is the batch-analyzed (i) batch sorption limit, $q_{i . e}$ is the sorption capability evaluated from the $\mathrm{q}_{\mathrm{i}}$-analyzed sorption model, and $\mathrm{n}$ is the batch-analyzed perception quantity.

The second statistical method is the chi-squared test $\left(\mathrm{X}^{2}\right)$ equation, which is the total sum of the squares of the differences between the experimental data acquired through model analysis. Each square variance is divided by the corresponding data obtained through model measurement. There is some comparability of the chi-squared test with the root mean square error and as follows:

$$
\mathrm{X}^{2}=\sum_{i=1}^{n} \frac{\left(q_{i}-q_{i . e}\right)^{2}}{q_{i . e}}
$$

The third statistical method is the number of absolute errors (SAE). In this method, the average of the maximum errors (SAE) is given as: 


$$
\mathrm{SAE}=\sum_{i=1}^{n}\left|q_{i}-q_{i . e}\right|_{i}
$$

The isotherm parameters managed using this method provide a better fit. The error increment size increases, biasing the fit to the high concentration information.

The fourth statistical method is the average relative error (ARE) defined as:

$$
\mathrm{ARE}=\frac{100}{n} \sum_{i=1}^{n}\left|\frac{q_{t}-q_{i . e}}{q_{t}}\right|
$$

This error function tries to restrict the propagation of fractional errors across the entire concentration array.

\section{Results and Discussion}

\subsection{Characterization of $m-C S / N C$ Abs.}

The prepared aerogel is consisting of chitosan (CS), nanocellulose (NC), and ferric oxide nanoparticles $\left(\mathrm{Fe}_{2} \mathrm{O}_{3} \mathrm{NPs}\right.$ ). Chitosan and nanocellulose are required to prepare the aerogels beads to be used in the color removal from wastewater. Chitosan is needed during the preparation of aerogel to combine with nanocellulose via reaction with its amino group with aldehyde group of nano cellulose and the electrostatic interaction with RB5 (which was formed during the preparation of nanocellulose) based on the Schiff base reaction [59-62]. Also, adding $\mathrm{Fe}_{2} \mathrm{O}_{3} \mathrm{NPs}$ is required for changing the properties of aerogel to be magnetic aerogel, which will help in adsorption rate and activity. Besides, the presence of the $\mathrm{Fe}_{2} \mathrm{O}_{3} \mathrm{NPs}$ is helping in the separation of aerogel particles by applying a magnetic effect, as shown in Figure 1.

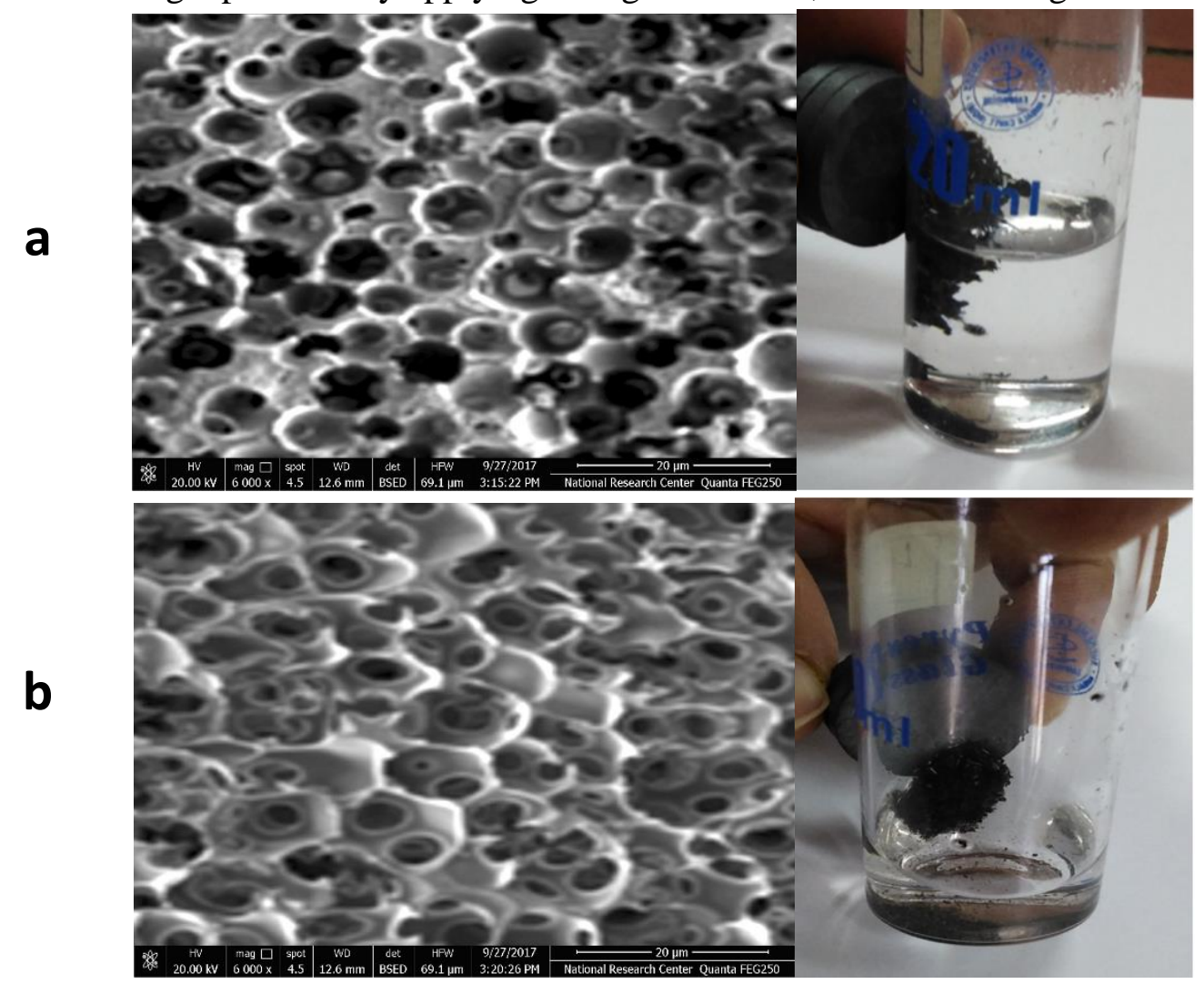

Figure 1. Images of the aerogel beads and their magnetic behavior of prepared aerogel: (a) CS/NC Abs-P; (b) CS/NC Abs-C. 
Nitrogen adsorption-desorption isotherms at liquid nitrogen temperatures were obtained for NC, aerogels obtained by cross-linked and deposition methods, as shown in Figure 2. For both relative pressures below 0.1 and between 0.4 and 1.0, respectively, two different regions (microporous and mesoporous regions) are found in the curves. In the mesoporous zone, the isothermal curves display a hysteresis defined as a pore diameter between 20 and $50 \mathrm{~nm}$. This was formed in the mesoporous as a result of nitrogen condensation. Results of acidification contribute to pure ferric nanoparticles of less than $30 \mathrm{~nm}$ in diameter. Such ferric nanoparticles are the same size as porous [63].

One of the important properties is the special surface area for the $\mathrm{NC}$ and the two aerogels. Table 1 provides the specific area and diameter of the surface for the aerogels developed by NC. Although the microporous specific surface area values measured using BET analysis are approximately 105,317 , and $214 \mathrm{~m}^{2} / \mathrm{g}$ with $44.8,23.7$, and $30.3 \mathrm{~nm}$ pore diameter for $\mathrm{NC}$, cross-linked and deposition aerogels methods, respectively [63]. The results presented in Table 1 show that $\mathrm{NC}$ has a smaller specific surface area with $105 \mathrm{~m}^{2} / \mathrm{g}$ than both aerogels with cross-linked or deposition methods (317 and $214 \mathrm{~m}^{2} / \mathrm{g}$ ). Such effects can be due to the small particle diameter and drying efficiency.

However, swelling percent measurements can provide a convenient way to assess composite aerogel hydrophilicity, m-CS/NC ABs-P, and m-CS/NC ABs-C compared to NC, as shown in Table 1. It is also observed that the percentage of swelling in equilibrium increased from the starting product, NC $(125 \%)$ to aerogel by an m-CS/NCABs-P $(480.22 \%)$ to aerogel by m-CS/NCABs-P (638\%). Such values demonstrate that the inclusion of magnetic chitosan can afford a range of hydrophilic sites associated with an increase in cellulose fibers ' polydipersability.

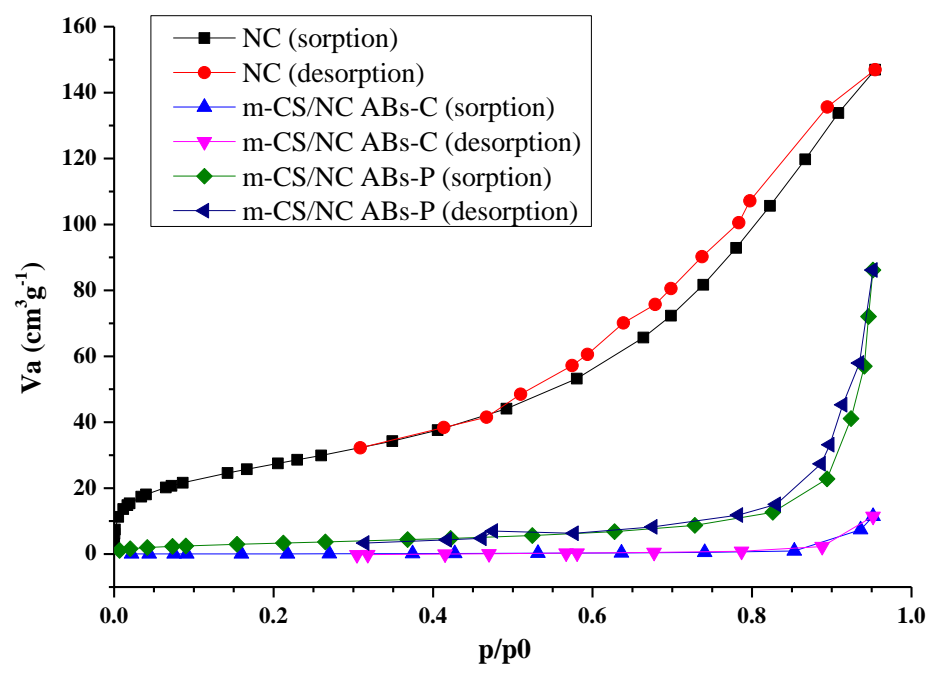

Figure 2. Nitrogen isotherms (adsorption-desorption curves) at - $195^{\circ}$ for $\mathrm{NC}, \mathrm{m}-\mathrm{CS} / \mathrm{NC}$ ABs-C, and $\mathrm{m}-\mathrm{CS} / \mathrm{NC}$ ABs-P methods.

Table 1. Physical properties for NC, $m-C S / N C$ ABs-C and m-CS/NC ABs-P methods.

\begin{tabular}{c|c|c|c|c|c|c}
\multirow{2}{*}{ Samples } & \multicolumn{3}{|c|}{ Swelling behavior } & BET Surface & $\begin{array}{c}\text { Total pore } \\
\text { Area }\left(\mathbf{m}^{2} / \mathbf{g}\right)\end{array}$ & $\begin{array}{c}\text { Mean pore } \\
\text { volume }\left(\mathbf{m}^{3} / \mathbf{g}\right)\end{array}$ \\
\cline { 2 - 3 } diameter $(\mathbf{n m})$
\end{tabular}

By using SEM as shown in Figure 3, the morphology and microstructure of NC and $\mathrm{m}-\mathrm{CS} / \mathrm{NC} \mathrm{ABs}$ are observed. The SEM micrograph of m-CS/NC ABs (Figure 3d, g) comprised networks of nano-fibers and exhibited uniform porous morphology. On the other hand, due to nano-fibers' aggregation, NC shapes are irregular, and their surfaces are fairly rough. In the case of the cross-linking process, the surfaces of aerogels nano-fibers networks are found to be thicker and rougher (Figure $3 \mathrm{~g}$ ). 
The well and uniform developed pores on the surface of $\mathrm{m}-\mathrm{CS} / \mathrm{NC} \mathrm{ABs}$ either the use of precipitation or cross-linking method, may lead to large pore diameter and increase the opportunity of dye trapping and adsorption. The energy dispersive X-ray (EDX) spectrum (Figure 3f, i) indicates the presence of carbon (C) and iron (Fe) elements in the sample by verifying the existence of $\mathrm{Fe}_{3} \mathrm{O}_{4}$ nanoparticles on the nano-fibers ' surfaces. The presence of high individual particles of $\mathrm{Fe}_{3} \mathrm{O}_{4}$ nanoparticles on $\mathrm{m}-\mathrm{CS} / \mathrm{NC}$ ABs-C surface compared to m$\mathrm{CS} / \mathrm{NC}$ ABs-P in SEM (Figure 3d) is well-matched with the results of EDX spectrum (Figure 3f). This may be attributed to the precipitation method's shielding effect on the EDX spectrum of some individual $\mathrm{Fe}_{3} \mathrm{O}_{4}$ nanoparticles.

Figure $3 \mathrm{~b}$, e, h shows TEM micrographs of the original NC, m-CS/NC ABs-P and m$\mathrm{CS} / \mathrm{NC} \mathrm{ABs}-\mathrm{C}$. TEM revealed that $\mathrm{NC}$ g have aggregated clusters included the nanocellulose crystals which are rigidly bounded. It has appeared that the particle size of NC is ranged from $5-41 \mathrm{~nm}$. Besides, both aerogels are heterogeneously distributed with an average size ranged from $26-50 \mathrm{~nm}$ and showed that $\mathrm{Fe}_{3} \mathrm{O}_{4}$ nanoparticles were embedded or trapped as dark spots into the m-CS/NC ABs-C. On the other hand, $\mathrm{Fe}_{3} \mathrm{O}_{4}$ nanoparticles seemed to cover the surface of $\mathrm{m}-\mathrm{CS} / \mathrm{NC}$ ABs-P during the precipitation method. This may be attributed to the higher proportion of individual and free $\mathrm{Fe}_{3} \mathrm{O}_{4}$ nanoparticles in the precipitation method than the cross-linking method. The results also showed that during the creation of aerogel, the iron oxide nanoparticles remained uniform and embedded in the composite matrix, without producing agglomerates that would influence their magnetic properties.

VSM was used to test the magnetic properties of $\mathrm{m}-\mathrm{CS} / \mathrm{NC} \mathrm{ABs}$ aerogel. Figure 4 demonstrates comparative magnetization outcomes of m-CS / NC ABs-P and m-CS / NC ABs-C. It is worth mentioning that $\mathrm{NC}$ crystals that have been applied to the m-CS surface cause an increase in particle weight and, therefore, a decrease in magnetic material content.
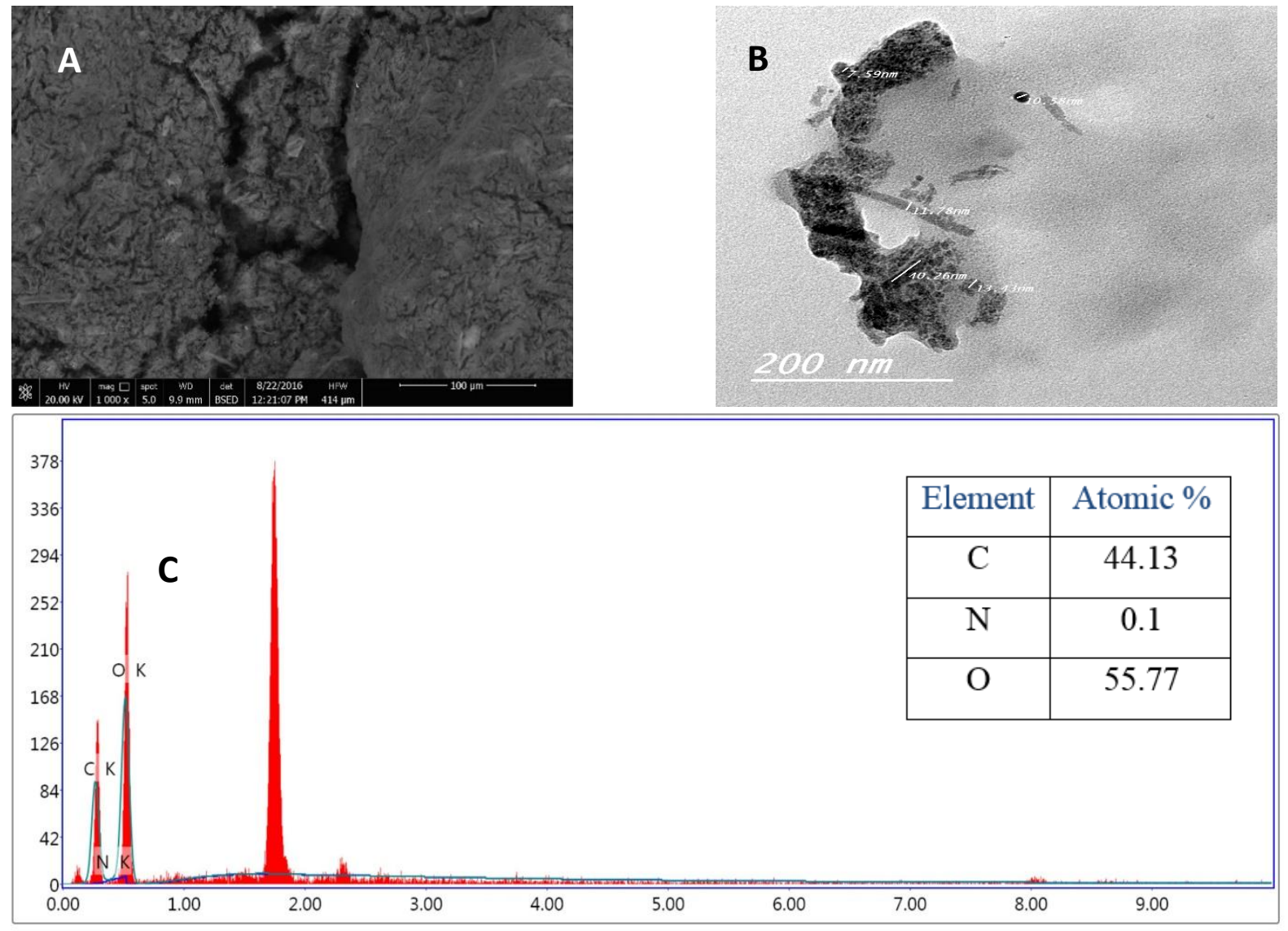

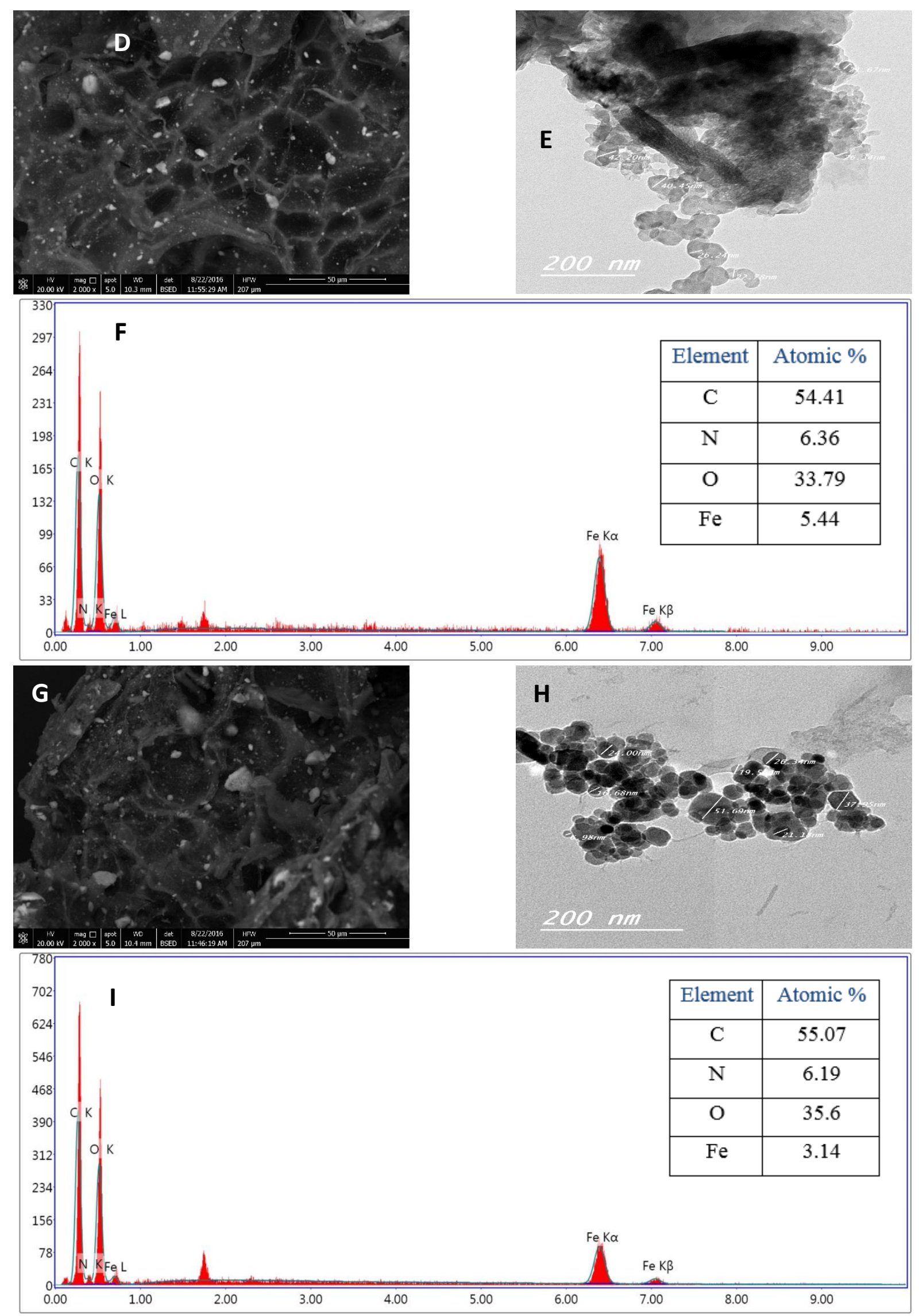

Figure 3. SEM, TEM and EDX images of (a-c) NC; (d-f) m-CS/NC ABs-C; (g-i) m-CS/NC ABs-P.

The magnetic property of each m-CS was studied by Dodi et al. [32]. It has a $26 \mathrm{emu} / \mathrm{g}$ saturated magnetization. The findings of this study's magnetic characterization were compared with those recorded for $\mathrm{m}-\mathrm{CS}$ by Dodi et al. [32]. The results showed that for $\mathrm{m}-$ 
CS / NC ABs-P and m-CS / NC ABs-C, respectively, the saturated magnetization values decreased to 18.5 and $21.3 \mathrm{emu} / \mathrm{g}$. Some of the decreases in magnetization may be due to the nanocrystal's cellulosic nano-fibers ' diamagnetic contribution. This result may be ideal for quick response to an external magnetic field and easy removal of aerogel after adsorption from the liquid phase.

It is a fact that the precipitation reactions in the aerogel formation by using $\mathrm{m}-\mathrm{CS} / \mathrm{NC}$ ABs-P increase the nonmagnetic material, which in turn decreases the final magnetization [35]. On the other hand, as in m-CS/NC ABs-C, the lower magnetization levels could be tentatively due to an increased magnetic substance crystallinity. It represents CS/NC ABsC's lower saturation magnetization than m-CS / NC ABs-P.

The FT-IR spectra for nano cellulose presented in Figure 4 a provide the presence of the cellulose characteristic peaks. There are two peaks linked at 3454 and $2888 \mathrm{~cm}^{-1}$, respectively, to $\mathrm{O}-\mathrm{H}$ and $\mathrm{C}-\mathrm{H}$ spreading vibrations. The $\mathrm{O}-\mathrm{H}$ vibration of absorbed liquid is related to another level at $1644 \mathrm{~cm}^{-1}$. Furthermore, there are two peaks at $1382 \mathrm{~cm}^{-1}$ for $\mathrm{C}-\mathrm{H}$ and $\mathrm{C}-\mathrm{O}$ signals from cellulose's polysaccharide rings. However, the presence of a peak at $1060 \mathrm{~cm}^{-1}$ characterizes the movement of $\mathrm{C}-\mathrm{O}-\mathrm{C}$ in the pyranose ring. [64-66] Furthermore, a peak appeared at $1731.67 \mathrm{~cm}^{-1}$ in the spectrum of $\mathrm{NC}$ is a characteristic peak of $\mathrm{C}=\mathrm{O}$ from dialdehyde cellulose

Figure $4 \mathrm{~b}$ and $\mathrm{c}$ show the FTIR spectra of m-CS / NC ABs-P and m-CS / NC ABs-C. The estimate that includes $\mathrm{Fe}_{3} \mathrm{O}_{4}$ 's signature absorption band in the $590 \mathrm{~cm}^{-1}$ composites is from $\mathrm{Fe}_{3} \mathrm{O}_{4}$ 's Fe-O extension. Crosslinking of chitosan and nanocellulose with glutaraldehyde dialdehyde is due to the high maximum at $1633 \mathrm{~cm}^{-1}$ form-CS / NC ABs-C.
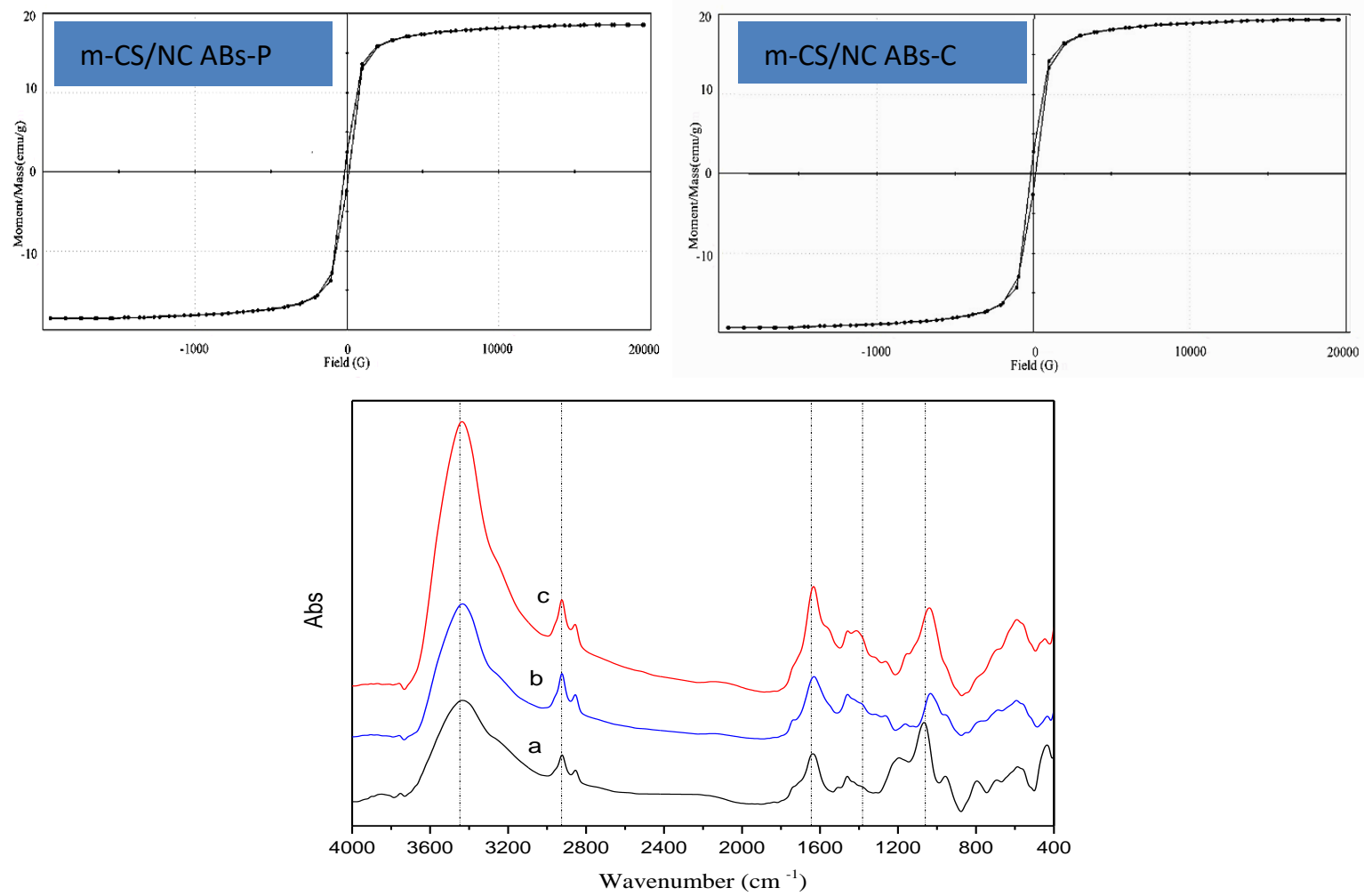

Figure 4. Magnetization measurements and FTIR spectra of (a) NC; (b) m-CS/NC ABs-P; (c) m-CS/NC ABsC.

The figure also contains the distinctive chitosan absorption bands shown at 3300-3400 (O-H and $\mathrm{N}-\mathrm{H}$ stretching vibrations), 2874 (C-H stretching vibrations), and the presence of a peak at $1151 \mathrm{~cm}^{-1}$ for the $\mathrm{C}-\mathrm{N}$ stretching vibration, which shows that amine groups exist in 
the composites. It was found that all the chitosan in the final products were chemically bonded to the magnetic nanoparticles and the m-CS had a shield effect on the final composite vibration suggesting the actual aerogel coating by $\mathrm{m}$-CS. This is confirmed by the magnetization properties tests.

The $\mathrm{pH}$ imparts a net positive or negative charge on $\mathrm{m}-\mathrm{CS} / \mathrm{NC}$ ABs-P or $\mathrm{m}-\mathrm{CS} / \mathrm{NC}$ $\mathrm{ABs}-\mathrm{C}$, thereby inducing intra- and intermolecular repulsions in composites. The high surface charge led to intermolecular repulsions and resulted in a stable and more uniform suspension through the solutions. This increases the potential utility of adsorbents for color removal. On the other hand, a low surface charge may lead to precipitation.

As shown in Figure 5, m-CS/NC ABs-P or m-CS/NC ABs-C show an increase in the zeta potential as the $\mathrm{pH}$ is increased from 2 to 4 , reaching a peak value around $\mathrm{pH} 4$ before the sudden decrease of zeta potential beyond $\mathrm{pH}$ 7. The $\mathrm{pH}$ of the acid medium (2-6) produced a net positive charge on $\mathrm{m}-\mathrm{CS} / \mathrm{NC} \mathrm{ABs}-\mathrm{P}$ or $\mathrm{m}-\mathrm{CS} / \mathrm{NC} \mathrm{ABs}-\mathrm{C}$. This may be attributed to the protonation of the amino group of $\mathrm{m}-\mathrm{CS}$ in composites. The decrease in the zeta potential below the peak $\mathrm{pH}$ value can be attributed to the counterions $\left(\mathrm{CH}_{3}-\mathrm{COO}^{-}\right)$added to the solution while adjusting $\mathrm{pH}$. A further increase in $\mathrm{pH}$ above 7 leads to the formation of an isoelectric point for $\mathrm{m}-\mathrm{CS} / \mathrm{NC} \mathrm{ABs}-\mathrm{P}$ or $\mathrm{m}-\mathrm{CS} / \mathrm{NC}$ ABs-C around $\mathrm{pH} 7-8$, where a net negative charge has been produced.

As the results of zeta potential measurements for the starting material, NC evidenced a negative value of $-31.2 \mathrm{mV}$ at $\mathrm{pH} 4$ compared with the peak values obtained for $\mathrm{m}-\mathrm{CS} / \mathrm{NC}$ ABs-P or $\mathrm{m}-\mathrm{CS} / \mathrm{NC} \mathrm{ABs}-\mathrm{C}$ at 43.5 and $48.1 \mathrm{mV}$, respectively. This is attributed to that the number of accessible surface amino groups in $\mathrm{m}-\mathrm{CS}$ is available for anionic color removal. This brings us to develop our experimental set-in color removal at $\mathrm{pH} 4$. Here too, the net positive charge confirmed the actual coating of aerogel composites by m-CS.

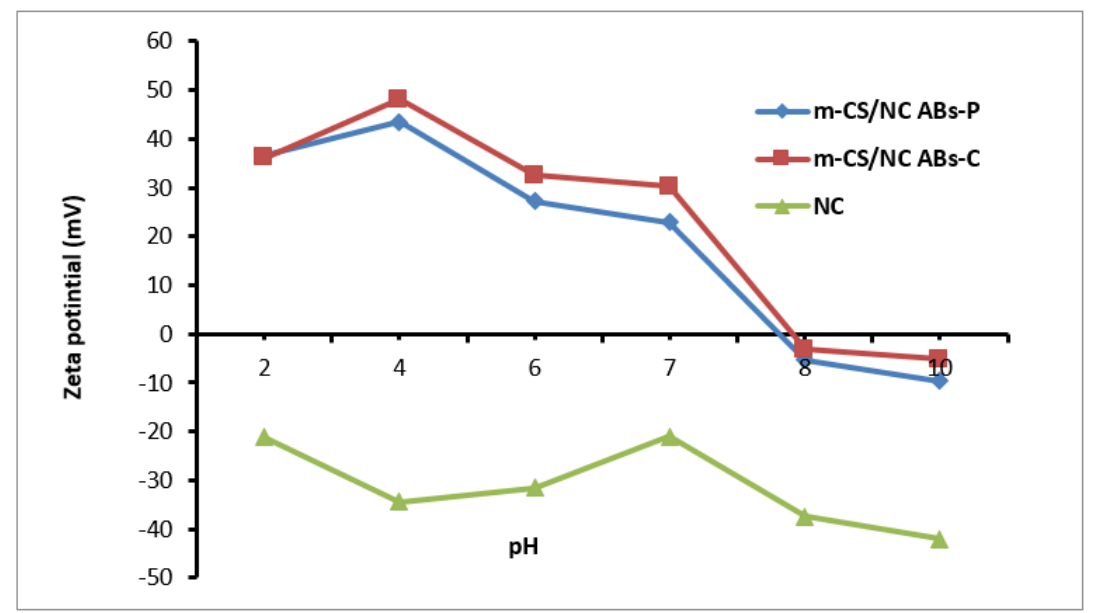

Figure 5. Zeta potential of $\mathrm{NC}, \mathrm{m}-\mathrm{CS} / \mathrm{NC}$ ABs-P and m-CS/NC ABs-C at different $\mathrm{pH}$.

\subsection{Effect of adsorbent dosage on the percentage of RB5 color removal.}

The effect of $\mathrm{m}-\mathrm{CS} / \mathrm{NC}$ ABs-P, m-CS/NC ABs-C, and NC dosage at different concentrations $(0.5-20 \mathrm{~g} / \mathrm{l})$ on RB5 color removal was studied.

The actual $\mathrm{pH}$ of the wastewater in the dye industry has been considered and was carried out at $\mathrm{pH} 3-4$, which matched the peak $\mathrm{pH}$ values for $\mathrm{m}-\mathrm{CS} / \mathrm{NC} \mathrm{ABs}-\mathrm{P}, \mathrm{m}-\mathrm{CS} / \mathrm{NC}$ ABs-C. The possibility of comparing the efficiency of tested aerogel sorbents with NC was undertaken at the same conditions. The percentage of color removal of RB5versus the dosage 
of tested adsorbents is shown in Figure 6A. The results showed that the color removal $\%$ of RB5 was linearly proportional to the amount of $\mathrm{m}-\mathrm{CS} / \mathrm{NC}$ ABs-based adsorbent.

It was also shown that the minimum initial concentrations required for the largest color removal efficiency could be attained at 2 and $4 \mathrm{~g} / \mathrm{l}$ for $\mathrm{m}-\mathrm{CS} / \mathrm{NC} \mathrm{ABs}-\mathrm{P}$ and $\mathrm{m}-\mathrm{CS} / \mathrm{NC}$ ABs-C, respectively. In this dosage condition, the color removal \% was estimated to be 95.17 and 92.18. During the precipitation, method, preparation of $\mathrm{m}-\mathrm{CS} / \mathrm{NC}$ ABs-P, a large excess of chitosan would be completely covered the surface of $\mathrm{Fe}_{3} \mathrm{O}_{4}$ nanoparticles. Assuming that the free amino groups of chitosan, which are the active sites for the electrostatic attraction with RB5, the color removal reaction of magnetic chitosan on the surface of aerogel in $\mathrm{m}$ $\mathrm{CS} / \mathrm{NC}$ ABs-P, will be much faster than $\mathrm{m}-\mathrm{CS} / \mathrm{NC} \mathrm{ABs}-\mathrm{C}$ at a low amount of adsorbent.

Besides, the absence of internal diffusion resistance in $\mathrm{m}-\mathrm{CS} / \mathrm{NC}$ ABs-P compared to cross-linked aerogel can be considered. By meaning, fewer amounts of magnetic chitosan are effectively bound on the surface of $\mathrm{m}-\mathrm{CS} / \mathrm{NC}$ ABs-C at initial concentration $<4 \mathrm{~g} / \mathrm{l}$. Based on the dosage of aerogel adsorbents, the highest color removal (\%) of RB5 near $100 \%$, for both for $\mathrm{m}-\mathrm{CS} / \mathrm{NC}$ ABs-P and $\mathrm{m}-\mathrm{CS} / \mathrm{NC} \mathrm{ABs}-\mathrm{C}$ was achieved at an initial concentration of adsorbent, 4 and $8 \mathrm{~g} / \mathrm{l}$ (Figure 6). The improvement in color removal (percentage) with increased dosage of aerogel adsorbents was attributed to the availability at a higher dose of more surface-efficient types.

The further increase in aerogel concentration above $8 \mathrm{~g} / \mathrm{l}$ has no major (percent) effect on color removal. It has not negatively impacted the peak adsorption efficiency at $8 \mathrm{~g} / \mathrm{l}$. This can be related to the equilibrium reached when aerogels' potential is stabilized or higher concentration due to the self-crosslinking of magnetic chitosan. The lack of affinity for RB5 removal of unmodified NC was predicted. Since the unmodified NC accumulated a net negative charge on its surface due to an excess of $\mathrm{OH}^{-}$, the active site will not be eligible for color extraction of anionic dye, and the electrostatic repulsion will be lower. $[67,68]$

\subsection{Effect of $\mathrm{pH}$ on the percentage of color removal.}

The $\mathrm{pH}$ of the solution is the most important factor influencing the phase of adsorption. [63] On the three adsorbents tested, Figure 6B shows the effect of $\mathrm{pH}$ on the extraction efficiency of dye RB 5, using 4 and $8 \mathrm{~g} \mathrm{~L}^{-1}$ for $\mathrm{m}-\mathrm{CS} / \mathrm{NC}$ ABs-P and $\mathrm{m}-\mathrm{CS} / \mathrm{NC}$ ABs-C, respectively. Studies clearly showed that the dye RB 5 adsorbed more effectively at $\mathrm{pH} 4(\sim 100 \%)$ on non-crosslinked aerogel fiber, CS/NC ABs-P. The adsorption gradually decreased with a $\mathrm{pH}$ rise above 6 . The weakly acidic solution led to an increase in $\mathrm{H}+$, which in turn increases the electrostatic attraction between negatively charged dye anions and positively charged CS/NC ABs-P layer.

This reflects the general trend of reducing anionic adsorbent removal performance on positively charged adsorbents while increasing the solution's $\mathrm{pH}$ level. This can be due to the more repulsive contact arising from $\mathrm{OH}^{-1}$ s excess [7]. However, the drop-in dye extraction at $\mathrm{pH}$ below 4 could be due to the association dominance of the intermolecular hydrogen bond between CS and NC. It is also evident that the aerogel adsorbent is cross-linking, CS / NC ABs-C, accelerates the dye adsorption cycle irrespective of the $\mathrm{pH}$ quality of the equilibrium solution.

It seems likely that the percentage elimination of $\mathrm{RB} 5$ on the $\mathrm{CS} / \mathrm{NC} \mathrm{ABs}-\mathrm{C}$ stays nearly constant with the $\mathrm{pH}$ rise from 1 to 6 and then declines significantly with the $\mathrm{pH}$ from 6 to 10. It is worth mentioning that cross-linking has a significant impact on the sorption process's efficacy. In general, the cross-linking resists the charge of $\mathrm{pH}$ relevant to color 
removing $\%$. This could be attributed to the participation of hydroxyl groups of CS/NC ABs$\mathrm{C}$ in cross-linking, which reflects the interaction between negatively charged by anions and positively charged CS/NC ABs-C.
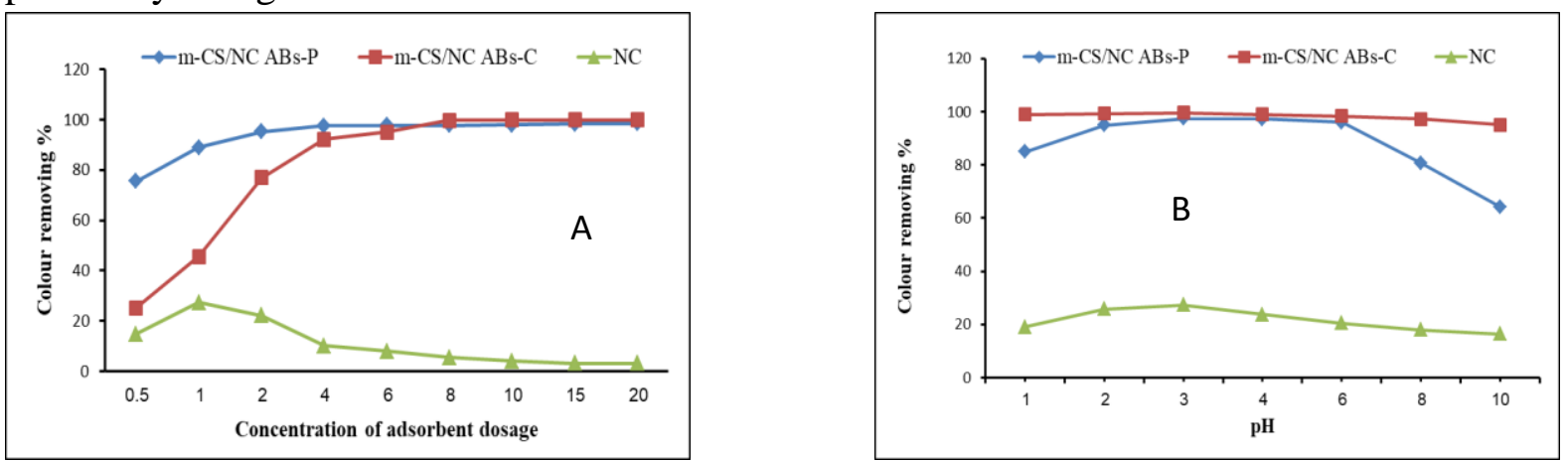

Figure 6. Effect of adsorbent dosage on the color removal (\%) of RB5. (A) Initial dye concentration (100 mg/l); $\mathrm{pH}=3-4$, and shacking time for $60 \mathrm{~min}$ at room temperature; (B) Initial dye concentration $(100 \mathrm{mg} / \mathrm{l}), 1 \mathrm{~g} / \mathrm{l} \mathrm{NC}, 4$ $\mathrm{g} / \mathrm{l}$ of CS/NC ABs-P and $8 \mathrm{~g} / \mathrm{l}$ of CS/NC ABs-C shaking time for $60 \mathrm{~min}$ at room temperature.

\subsection{Effect of contact time on the percentage of color removal}

Figure 7 shows the effect of time on the efficacy of CS / NCABs-based adsorbents for extracting RB5 at different initial dye concentrations. An important factor in the treatment process is the original concentration of the pigment. It is strongly recommended that the lowest concentrations of RB5 in solution achieve full stain removal regardless of the type of adsorbent. It is also apparent that the proportion of color elimination decreased as the contact time increased, regardless of the type of adsorbent, from 10 to $60 \mathrm{~min}$. Nonetheless, for CS/NCABs-C and CS/NCABs-P, respectively, the substantial optimum contact time was achieved for the adsorption equilibrium at 60 and $90 \mathrm{~min}$. To this point, it was assumed that the cross-linking enhanced the adsorption capacity at a low supplied contact time to accomplish the maximum color removal ( 100\%).

It is worth noting that the change in time will increase the chance of electrostatic interaction between anionic dye and adsorbents based on CS/NCABs. So, it might be possible to adsorb a large number of dye molecules. It is clear from Figure 7 that the further rise in contact time above 60 and $90 \mathrm{~min}$ for CS/NCABs-C and CS/NCABs-P, respectively, have no increase in color extraction rate.
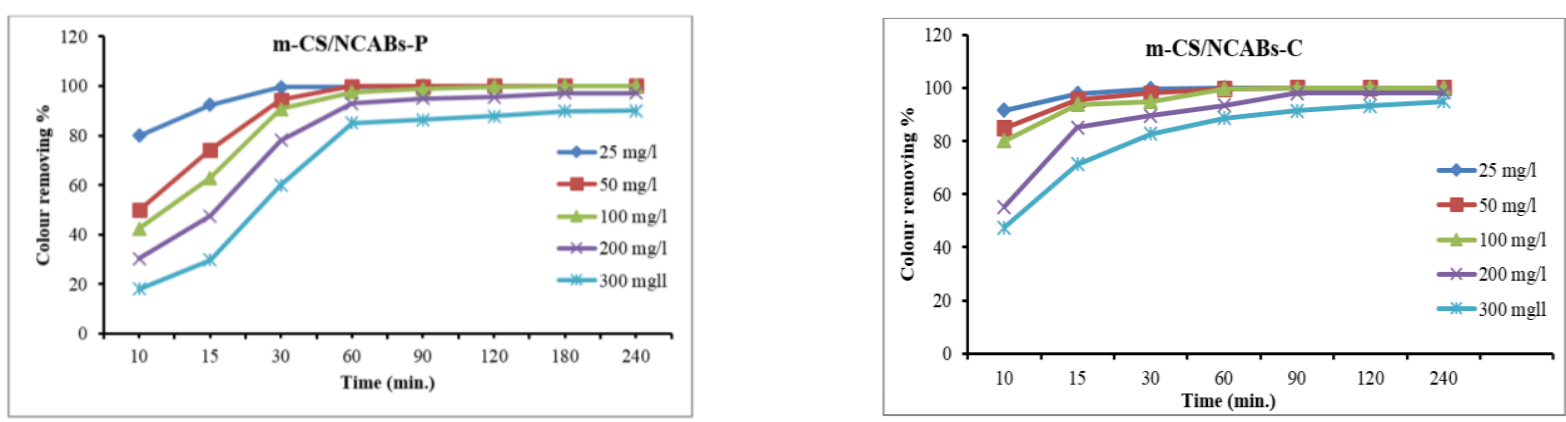

Figure 7. Effect of contact time on the color removal (\%) of RB5. Initial adsorbent concentration $4 \mathrm{~g} / \mathrm{l}$ $\mathrm{CS} / \mathrm{NCABs}-\mathrm{P}$ and $8 \mathrm{~g} / \mathrm{l} \mathrm{CS} / \mathrm{NCABs}-\mathrm{C}, \mathrm{pH}=3-4$ and were shaken for a different time at room temperature.

\subsection{Reusability of $m-C S / N C A B s$ with the adsorbed RB5 as a pigment color in textile printing.}

The reusability of natural aerogel adsorbents with adsorbed colors in another product source, pigment printing, is considered an important economic factor to minimize the expense of the adsorption process and prevent secondary contamination due to the adsorbed color if 
$\mathrm{m}-\mathrm{CS} / \mathrm{NC} \mathrm{ABs}$ was recovered and used for the next loading adsorption cycle. The potential utility of using $\mathrm{m}-\mathrm{CS} / \mathrm{NC} \mathrm{ABs}$ can rely on its reusability in textile pigment printing with the sustainable application. For this in mind, the m-CS/NC ABs colored powders were used as a pigment to print silk, wool, and cotton using the pigment printing technique.

After Drying and curing the printed fabrics, they are cleaned, at last, followed by drying. Figure 8 indicates that the fabric specimens were successfully printed using the pigment printing process with the m-CS / NC ABs colored powders and obtained a fair color tone. This fact indicated that the composite aerogel could be used as reusable adsorbents in another application source and avoiding secondary pollution [51].

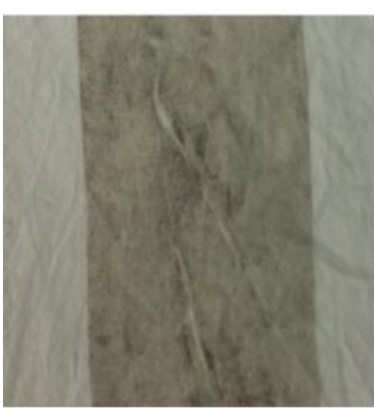

silk

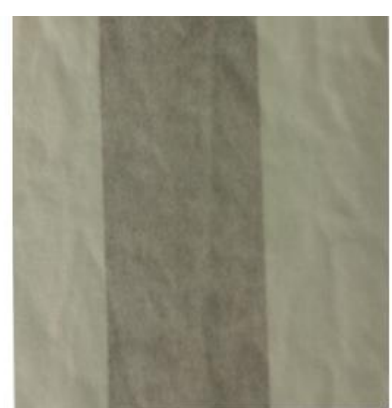

wool

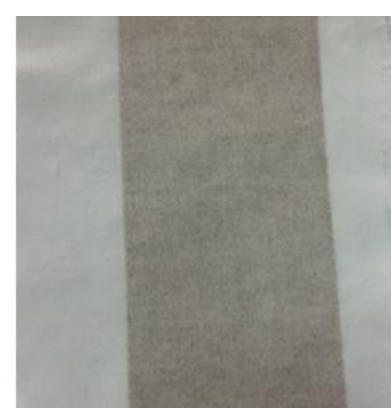

polyester

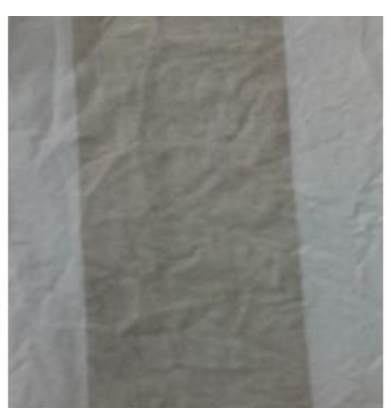

cotton

Figure 8. Printed fabrics with m-CS/NC ABs colored powders by using the pigment printing method.

The introduction of aerogels to the textile fabrics affects the fabrics' mechanical properties but with small changes, which can be neglected. Furthermore, the treated fabrics' color strength with aerogels has been measured after repeated washing cycles, which provides a small decrease after 10 washing cycles for all treated fabrics with both aerogels. Further washing did not affect the color strength of all treated fabrics. Moreover, the data on mechanical properties and color strength have been listed in Table 2.

Table 2. Mechanical properties and color strength after repeating the washing cycle for printed fabrics.

\begin{tabular}{|c|c|c|c|c|c|c|}
\hline \multirow{2}{*}{\multicolumn{2}{|c|}{ Fabric }} & \multicolumn{3}{|c|}{$\mathbf{K} / \mathbf{S}$} & \multirow{2}{*}{$\begin{array}{r}\text { Tensile } \\
\text { strength } \\
\left(\mathrm{N} / \mathrm{mm}^{2}\right)\end{array}$} & \multirow[b]{2}{*}{$\begin{array}{c}\text { Elongation at } \\
\text { a break }(\%)\end{array}$} \\
\hline & & $\begin{array}{c}\text { After } 1 \\
\text { washing }\end{array}$ & $\begin{array}{r}\text { After } 10 \\
\text { washing }\end{array}$ & $\begin{array}{l}\text { After } 25 \\
\text { washing }\end{array}$ & & \\
\hline \multirow{2}{*}{ Silk } & m-CS/NC ABs-P & 9.9 & 9.4 & 9.3 & 8.25 & 5.32 \\
\hline & m-CS/NC ABs-C & 10.3 & 9.6 & 9.3 & 8.31 & 5.38 \\
\hline \multirow{2}{*}{ Wool } & m-CS/NC ABs-P & 9.5 & 9.1 & 9 & 11.39 & 7.53 \\
\hline & m-CS/NC ABs-C & 10.2 & 9.8 & 9.6 & 11.37 & 5.55 \\
\hline \multirow{2}{*}{ Cotton } & m-CS/NC ABs-P & 11.9 & 11.6 & 11.2 & 14.25 & 7.33 \\
\hline & m-CS/NC ABs-C & 12.8 & 12.3 & 11.9 & 14.31 & 7.42 \\
\hline \multirow{2}{*}{ Polyester } & m-CS/NC ABs-P & 12.2 & 11.7 & 11.5 & 12.82 & 7.43 \\
\hline & m-CS/NC ABs-C & 11.8 & 11.4 & 11.2 & 12.84 & 6.49 \\
\hline
\end{tabular}

\subsection{Adsorption study.}

\subsubsection{Kinetic study.}

Adsorption efficiency and test feasibility are provided using helpful information from processes of kinetic adsorption. Figure 9 shows the concentration-time curves of RB5 adsorption on the prepared composite substrate, with each process having a different concentration. It's obvious from the chart that prepared composite with both methods (deposition or cross-linked) and different concentrations from 2.5 to $30 \mathrm{mg} / 100 \mathrm{ml}$ can adsorb RB5 with good exhausting from the dye bath solution. In addition, using composite (by crosslinking method) shows better absorption behavior than using the composite (by deposition 
method), especially at the first 20 mins which confirm that the prepared composite through cross-linking method has small cavities that have the opportunity to absorb the dye molecules and keep it inside its network more than the prepared composite through deposition method. In addition, in the composite prepared through the cross-linking method, absorption of dye molecules reaches the maximum capacity after about $20 \mathrm{~min}$. Further time shows a slight increase in dye absorption. But, in the case of prepared composite through deposition method, absorption of dye molecules reaches the maximum capacity after about 20, 20, 30, 60, 90 min for $2.5,5,10,20$, and $30 \mathrm{mg} / 100 \mathrm{ml}$ and further time shows slightly increasing in dye absorption.

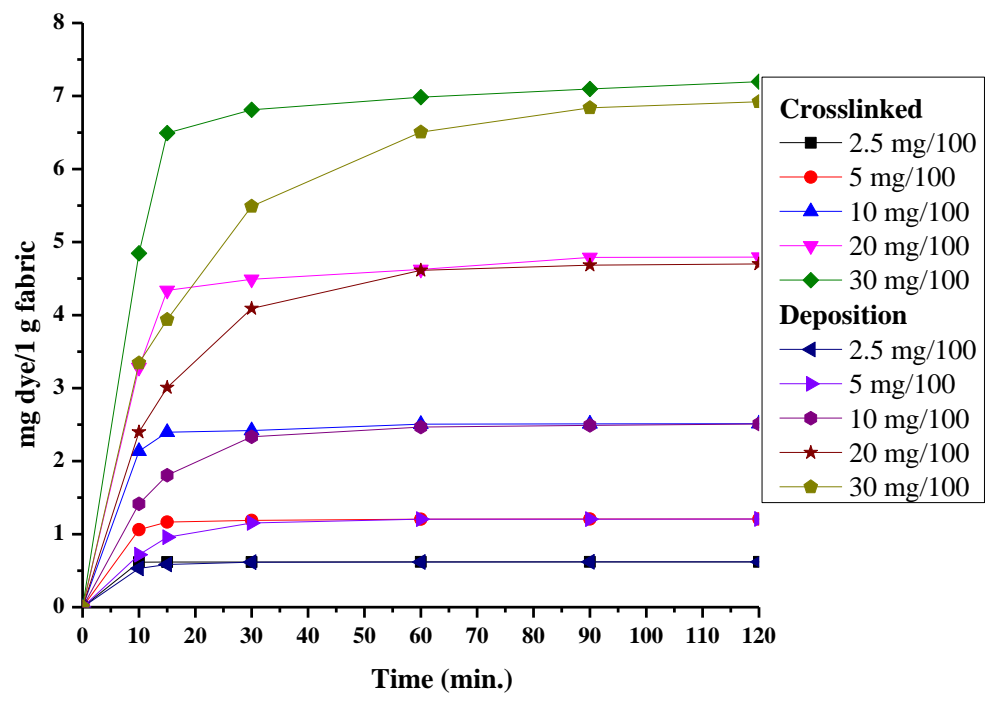

Figure 9. Contact time curves for both methods with different concentrations.

The values of the adsorption rate constant $(\mathrm{k})$, other parameters, and the correlation coefficient for RB5 adsorption on the aerogel composite based on nano-cellulose were determined for each plot from the kinetic adsorption processes.

Attaining the maximum linear relationship (the highest value of $\mathrm{R}^{2}$ ) is the value for the reaction's chosen order. Table 3 displays the respective values of rate constant $(k)$ and $R^{2}$ correlation coefficients. $\mathrm{C}_{\max }$ rose in the same direction with the data presented in Figure 9 from the data presented in Table 3. In short, as the concentration of processed material decreased from 2.5 to $30 \mathrm{mg} / 100 \mathrm{ml}$, the measured total dye efficiency (Cmax) consumed from the examined models increased from 0.84 to 7.19 and from 0.63 to 7.75 , respectively for pseudo-first and pseudo-second-order.

From Figure 9, these data are collected and tested. Both values are nearest to one from the correlation coefficient $\left(\mathrm{R}^{2}\right)$ values. However, it is much closer to one with pseudo-secondorder, so both techniques used (deposition and cross-linking methods) obey pseudo-secondorder with all concentrations. The second-order kinetic model suggests that mean micropores' adsorption process is a diffusional one [70,71].

Table 3. Kinetic parameter values from the experimental data.

\begin{tabular}{|c|c|c|c|c|c|c|c|c|c|}
\hline \multirow[t]{2}{*}{ Methods } & \multirow{2}{*}{$\begin{array}{l}\text { Conc. } \\
\mathrm{mg} / 100 \\
\mathrm{ml}\end{array}$} & \multicolumn{3}{|c|}{ Pseudo First Order } & \multicolumn{3}{|c|}{ Pseudo Second Order } & \multicolumn{2}{|c|}{$\begin{array}{l}\text { Cegarra } \\
\text { equation }\end{array}$} \\
\hline & & $k_{1}$ & $C_{\max }$ & $\mathbf{R}^{2}$ & $\mathbf{k}_{2}$ & $C_{\max }$ & $\mathbf{R}^{2}$ & $\mathbf{K}_{3}$ & $\mathbf{R}^{2}$ \\
\hline \multirow{5}{*}{$\begin{array}{l}\mathrm{m}-\mathrm{CS} / \mathrm{NC} \\
\mathrm{ABs}-\mathrm{P}\end{array}$} & 2.5 & 0.18 & 0.84 & 0.9998 & 0.15 & 0.63 & 0.9999 & 0.18 & 0.9998 \\
\hline & 5 & 0.11 & 1.09 & 0.9968 & 0.16 & 1.27 & 0.9994 & 0.11 & 0.9958 \\
\hline & 10 & 0.09 & 2.73 & 1 & 0.06 & 2.67 & 0.9985 & 0.09 & 1 \\
\hline & 20 & 0.06 & 4.44 & 0.9999 & 0.02 & 5.15 & 0.9999 & 0.06 & 0.9999 \\
\hline & 30 & 0.04 & 7.19 & 0.9979 & 0.01 & 7.75 & 0.9999 & 0.04 & 0.9979 \\
\hline
\end{tabular}




\begin{tabular}{|c|c|c|c|c|c|c|c|c|c|}
\hline \multirow[t]{2}{*}{ Methods } & \multirow{2}{*}{$\begin{array}{l}\text { Conc. } \\
\text { mg/100 } \\
\text { ml }\end{array}$} & \multicolumn{3}{|c|}{ Pseudo First Order } & \multicolumn{3}{|c|}{ Pseudo Second Order } & \multicolumn{2}{|c|}{$\begin{array}{r}\text { Cegarra } \\
\text { equation }\end{array}$} \\
\hline & & $\mathbf{k}_{1}$ & $C_{\max }$ & $\mathbf{R}^{2}$ & $\mathbf{k}_{2}$ & $\mathbf{C}_{\max }$ & $\mathbf{R}^{2}$ & $K_{3}$ & $\mathbf{R}^{2}$ \\
\hline \multirow{5}{*}{$\begin{array}{l}\mathrm{CS} / \mathrm{NC} \\
\mathrm{ABs}-\mathrm{C}\end{array}$} & 2.5 & 0.06 & 1.21 & 0.9273 & 0.28 & 0.62 & 1 & 0.05 & 0.9297 \\
\hline & 5 & 0.06 & 2.11 & 0.9978 & 0.87 & 1.22 & 0.9999 & 0.06 & 0.9978 \\
\hline & 10 & 0.04 & 2.22 & 0.9928 & 0.28 & 2.55 & 0.9999 & 0.07 & 0.9289 \\
\hline & 20 & 0.02 & 1.61 & 0.9928 & 0.06 & 4.95 & 0.9994 & 0.02 & 0.9928 \\
\hline & 30 & 0.02 & 1 & 0.9496 & 0.04 & 7.4 & 0.9994 & 0.02 & 0.9496 \\
\hline
\end{tabular}

3.6.2. Isothermal studies.

Adsorbed dye concentration ( $\mathrm{mg} / \mathrm{g}$ ) vs. different initial dye concentrations shown in Figure 9 shows that by increasing the dye concentration in the dye bath from 25 to 300 $\mathrm{mg} / 100 \mathrm{ml}$, the total adsorbed dye concentration has been improved. Langmuir, Freundlich, and BET designs are the most widely used cotton fabrics models [55,56]. Table 4 lists the isothermal system parameters with their regular errors. The Langmuir isotherm is commonly used to analyze single-solute structures and their prediction that intermolecular forces will decrease rapidly with separation and thus envisage monolayer dye coat on the formed aerogel's outer surface. The facilitating presumption is that adsorption occurs at different homogeneous sites of the aerogel surface generated. There is no broad interaction between adsorbed species. Freundlich isotherm helps characterize heterogeneity and has been used to analyze RB5 adsorption on the composite layer of aerogel. Brunauer-Emmett-Teller (BET) isotherm model is the third isotherm model used as part of this examination [58]. The data on adsorption was used to understand it. The technique was typically used to understand the dye's physical and chemical adsorption from its aqueous solution.

Table 4. Parameters of different adsorption isotherm.

\begin{tabular}{|c|c|c|c|c|}
\hline \multirow{2}{*}{ Methods } & \multirow{2}{*}{ Parameters } & \multicolumn{3}{|c|}{ Adsorption isotherm models } \\
\hline & & Langmuir isotherm & Freundlich isotherm & BET isotherm \\
\hline \multirow{8}{*}{$\mathrm{NC}$} & $\mathrm{K}$ & -14.24465409 & 6983.9320 & 9.769995235 \\
\hline & $\mathrm{C}_{\max }(\mathrm{mg}$ dye/g) & 6.289308176 & 0.699 & -6.967136019 \\
\hline & $1 / \mathrm{n}$ & & -0.6913 & \\
\hline & $\mathrm{R}^{2}$ & 0.9925 & 0.9053 & 0.9966 \\
\hline & RMSE & 948.096 & 762.688 & 769.306 \\
\hline & $\mathrm{X} 2$ & 730591.299 & 6657431.064 & -679570.084 \\
\hline & SAE & 3.212 & 28.929 & 67.260 \\
\hline & ARE & 4.846 & 44.542 & 104.400 \\
\hline \multirow{8}{*}{ m-CS/NC ABs-P } & $\mathrm{K}$ & 1.62 & 467.9506 & 4.907190413 \\
\hline & $\mathrm{C}_{\max }(\mathrm{mg}$ dye/g) & 100 & 0.699 & -0.135674165 \\
\hline & $1 / \mathrm{n}$ & & 0.1199 & \\
\hline & $\mathrm{R}^{2}$ & 0.9745 & 0.8725 & 0.9855 \\
\hline & RMSE & 849.757 & 762.688 & 763.408 \\
\hline & $\mathrm{X} 2$ & 36772.263 & 6657431.064 & -34364212.363 \\
\hline & SAE & 467.576 & 28.929 & 33.102 \\
\hline & ARE & 730.803 & 44.542 & 51.059 \\
\hline \multirow{8}{*}{$\mathrm{CS} / \mathrm{NC} \mathrm{ABs}-\mathrm{C}$} & $\mathrm{K}$ & 46.45 & 21.8776 & 4.643180237 \\
\hline & $\mathrm{C}_{\max }(\mathrm{mg}$ dye/g) & 250 & 0.699 & -0.3746862 \\
\hline & $1 / \mathrm{n}$ & & 0.6358 & \\
\hline & $\mathrm{R}^{2}$ & 1 & 0.9549 & 0.9593 \\
\hline & RMSE & 696.265 & 762.688 & 763.614 \\
\hline & $\mathrm{X} 2$ & 9856.826 & 6657431.064 & -12450031.753 \\
\hline & SAE & 1217.576 & 28.929 & 34.298 \\
\hline & ARE & 1902.008 & 44.542 & 52.926 \\
\hline
\end{tabular}


As it can see, the Langmuir adsorption model shows stronger $\mathrm{R}^{2}$ results than the other versions did. However, the fit to the Langmuir template indicates that RB5 dye can adsorb and form a monolayer on the active aerogel composite sites. It defined a positive adsorption state from Freundlich's template as $\mathrm{n}$ value $>1$, in this manner [72,73].

\subsubsection{Comparison with other frequently used adsorbents.}

Comparison of our aerogel composites prepared in the literature with other aerogel composite adsorbents was illustrated in Table 5. Table 5 shows that both prepared aerogel composites (through deposition or cross-linking methods) show higher adsorption capacity. Besides, it is close to that synthesized by Wang et al. [70]. Furthermore, chitosan/carbon nanotubes show higher adsorption capacity than prepared aerogel composites, but as carbon nanotubes' cost is higher than cellulose or chitosan, so, prepared aerogel composites are much cheaper and more eco-friendly. In the end, RB5 can effectively be removed from its solution using prepared aerogel composites with lower cost over a wide $\mathrm{pH}$ range.

Table 5. Capacity adsorption of aerogels from literature.

\begin{tabular}{l|c}
\multicolumn{1}{c|}{ Aerogels composites } & C \\
\hline Chitosan/carbon $(\mathbf{g})$ & 450.4 \\
\hline Chitosan/graphene oxide fibers [75] & 294.12 \\
\hline Chitosan/silica aerogels [76] & 150 \\
\hline Chitosan/montmorillonite nanocomposite [77] & 55 \\
\hline Cellulose/chitosan aerogels [70] & 381.7 \\
\hline Cellulose/chitosan aerogels (deposition method) & 359.2 \\
\hline Cellulose/chitosan aerogels (crosslinking method) & 364.2
\end{tabular}

\section{Conclusions}

Basic precipitation and cross-linking methods for removing RB5 from aqueous solutions have successfully produced magnetic and highly porous cellulosic aerogel extracted from rice straw waste. The morphology shows that during the development of aerogel, the iron oxide nanoparticles remained uniform and incorporated in the composite matrix without producing agglomerates. Saturated magnetization showed a drop in CS/NC ABs-C and m$\mathrm{CS} / \mathrm{NC}$ ABs-P magnetization relative to $\mathrm{m}-\mathrm{CS}$ due to the diamagnetic contribution of nanocellulose crystals nanofibers.

However, the tests also showed that the aerogels could be ideal for quick response to an external magnetic field and simple extraction of aerogel after adsorption from the liquid phase. On the other hand, in the zeta potential calculations, the higher surface charges of accessible surface amino groups in m-CS hit a peak value around $\mathrm{pH} 3-4$ and improve the possible utility of color extraction adsorbents. The highest color removal efficiency could be obtained at 4 and $8 \mathrm{~g} / \mathrm{l}$ for $\mathrm{m}-\mathrm{CS} / \mathrm{NC}$ ABs-P and $\mathrm{m}-\mathrm{CS} / \mathrm{NC}$ ABs-C, respectively.

In addition, the adsorption stays nearly constant with $\mathrm{pH}$ decreases from 1 to 6.0 , and marginally reduced with $\mathrm{pH}$ increases above 6 . Therefore, cross-linking is important and significantly impacts the sorption method's effectiveness at a low contact time to achieve full-color extraction $(\sim 100 \%)$. The possible usefulness of using the prepared aerogel can be related to its reusability in fabric pigment printing with green use and minimizing secondary contamination. 
It is evident from the kinetic information that, with all concentrations, all methods used (deposition and cross-linking methods) follow pseudo-second-order. In contrast, the second-order kinetic model suggests that the adsorption process by mean micro-pores is a diffusional one. On the other hand, the Langmuir adsorption model shows a better data fit than the other models.

\section{Funding}

This research received no external funding.

\section{Acknowledgments}

\section{We are gratefully thankful to National Research Centre, Egypt for provided facilities.}

\section{Conflicts of Interest}

The authors declare no conflict of interest.

\section{References}

1. Manikandan, B.; Ramamurthi, V.; Karthikeyan, R.; Sundararaman, T.R. Biobleaching of textile dye effluent using mixed culture through an immobilized packed bed bioreactor (IPBBR). Mod Appl Sci 2009, 3, 131135, http://dx.doi.org/10.5539/mas.v3n5p131.

2. Sharma, P.; Kaur, H.; Sharma, M.; Sahore, V. A review on applicability of naturally available adsorbents for the removal of hazardous dyes from aqueous waste. Environ. Monit. Assess. 2011, 183, 151-195, https://doi.org/10.1007/s10661-011-1914-0.

3. Elshemy, N.S.; Nassar, S.H.; El-Taieb, N.M.; Shakour, A.A.A.; Elmekawy, A.M.; Hassabo, A.G. Letters in Applied NanoBioScience 2019, 9, 682 - 691, https://doi.org/10.33263/LIANBS84.682691.

4. El-Zawahry, M.M.; Abdelghaffar, F.; Abdelghaffar, R.A.; Hassabo, A.G. Equilibrium and kinetic models on the adsorption of Reactive Black 5 from aqueous solution using Eichhornia crassipes/chitosan composite. Carbohydr. Polym. 2016, 136, 507-515, https://doi.org/10.1016/j.carbpol.2015.09.071.

5. Rangabhashiyam, S.; Anu, N.; Selvaraju, N. Sequestration of dye from textile industry wastewater using agricultural waste products as adsorbents. Journal of Environmental Chemical Engineering 2013, 1, 629641, https://doi.org/10.1016/j.jece.2013.07.014.

6. Du, Y.; Qiu, M. Comparative study of advanced oxidation for textile wastewater. Desalination and Water Treatment 2013, 51, 5954-5958, https://doi.org/10.1080/19443994.2012.763051.

7. Xu, X.; Gao, B.-Y.; Yue, Q.-Y.; Zhong, Q.-Q. Preparation and utilization of wheat straw bearing amine groups for the sorption of acid and reactive dyes from aqueous solutions. J. Hazard. Mater. 2010, 182, 1-9, https://doi.org/10.1016/j.jhazmat.2010.03.071.

8. Zhu, H.Y.; Fu, Y.Q.; Jiang, R.; Yao, J.; Xiao, L.; Zeng, G.M. Novel magnetic chitosan/poly(vinyl alcohol) hydrogel beads: Preparation, characterization and application for adsorption of dye from aqueous solution. Bioresour. Technol. 2012, 105, 24-30, https://doi.org/10.1016/j.biortech.2011.11.057.

9. Bora, T.; Dutta, J. Applications of Nanotechnology in Wastewater Treatment\&\#8212;A Review. Journal of Nanoscience and Nanotechnology 2014, 14, 613-626, https://doi.org/10.1166/jnn.2014.8898.

10. Zhu, L.; Zong, L.; Wu, X.; Li, M.; Wang, H.; You, J.; Li, C. Shapeable Fibrous Aerogels of Metal-OrganicFrameworks Templated with Nanocellulose for Rapid and Large-Capacity Adsorption. ACS Nano 2018, 12, 4462-4468, https://doi.org/10.1021/acsnano.8b00566.

11. Mohamed, A.L.; Hassabo, A.G. Flame retardant of cellulosic materials and their composites. 2015; $247-$ 314, http://dx.doi.org/10.1007/978-3-319-03467-6_10.

12. Mohamed, A.L.; Hassabo, A.G. Composite material based on pullulan/silane/ZnO-NPs as pH, thermosensitive and antibacterial agent for cellulosic fabrics. Advances in Natural Sciences: Nanoscience and Nanotechnology 2018, 9, 045005, https://doi.org/10.1088/2043-6254/aaeee0.

13. Hassabo, A.G.; El-Naggar, M.E.; Mohamed, A.L.; Hebeish, A.A. Development of multifunctional modified cotton fabric with tri-component nanoparticles of silver, copper and zinc oxide. Carbohydr. Polym. 2019, 210, 144-156, https://doi.org/10.1016/j.carbpol.2019.01.066.

14. Hassabo, A.G.; Mohamed, A.L. Novel flame retardant and antibacterial agent containing mgo nps, phosphorus, nitrogen and silicon units for functionalise cotton fabrics. Biointerface Research in Applied Chemistry 2019, 9, 4272 - 4278, https://doi.org/10.33263/BRIAC95.272278. 
15. Hassabo, A.G.; Shaarawy, S.; Mohamed, A.L.; Hebiesh, A. Multifarious cellulosic through innovation of highly sustainable composites based on Moringa and other natural precursors. Int. J. Biol. Macromol. 2020, 165, 141-155, https://doi.org/10.1016/j.ijbiomac.2020.09.125.

16. Mohamed AL, Hassabo AG, Review of silicon-based materials for cellulosic fabrics with functional applications, Journal of Textiles, Coloration and Polymer Science, 2019; 16: 139-157. https://doi.org/10.21608/JTCPS.2019.18580.1030.

17. Khattab TA, Mohamed AL, Hassabo AG, Development of durable superhydrophobic cotton fabrics coated with silicone/stearic acid using different cross-linkers, Materials Chemistry and Physics, 2020; 249. https://doi.org/10.1016/j.matchemphys.2020.122981.

18. Mohamed AL, Elmotasem H, Salama AAA, Colchicine mesoporous silica nanoparticles/hydrogel composite loaded cotton patches as a new encapsulator system for transdermal osteoarthritis management, Int. J. Biol. Macromol., 2020; 164: 1149-1163. https://doi.org/10.1016/j.ijbiomac.2020.07.133.

19. Mohamed AL, Soliman AAF, Ali EA, Abou-Zeid NY, Nada AA, Hydrogel bioink based on clickable cellulose derivatives: Synthesis, characterization and in vitro assessment, Int. J. Biol. Macromol., 2020; 163: 888-897. https://doi.org/10.1016/j.ijbiomac.2020.07.068.

20. Hassabo AG, Sharaawy S, Mohamed AL, Unsaturated fatty acids based materials as auxiliaries for printing and finishing of cellulosic fabrics, Biointerface Research in Applied Chemistry, 2019; 9: 4284 - 4291. https://doi.org/10.33263/BRIAC95.284291.

21. Yang, H.; Sheikhi, A.; van de Ven, T.G.M. Reusable Green Aerogels from Cross-Linked Hairy Nanocrystalline Cellulose and Modified Chitosan for Dye Removal. Langmuir 2016, 32, 11771-11779, https://doi.org/10.1021/acs.langmuir.6b03084.

22. Reddy, N.; Yang, Y. Properties of High-Quality Long Natural Cellulose Fibers from Rice Straw. J. Agric. Food Chem. 2006, 54, 8077-8081, https://doi.org/10.1021/jf0617723.

23. El Zawahry, M.M.; Hakeim, O.A.; Abdelghaffar, F.; El-Hawary, N.S. Modification of rice straw via polyelectrolyte layer-by-layer assembly for high performance dye adsorption. Research Journal of Chemical Sciences 2014, 2231, 606X.

24. Mohamed, A.L. Silan/biopolymer microgels for functionalization of cotton fabric: dual responsive $\mathrm{pH}$ and temperature and antibacterial properties. Journal of Applied Pharmaceutical Science 2017, 7, 077-088, http://doi.org/10.7324/JAPS.2017.70713.

25. Hui, M.; Shengyan, P.; Yaqi, H.; Rongxin, Z.; Anatoly, Z.; Wei, C. A highly efficient magnetic chitosan "fluid" adsorbent with a high capacity and fast adsorption kinetics for dyeing wastewater purification. Chem. Eng. J. 2018, 345, 556-565, https://doi.org/10.1016/j.cej.2018.03.115.

26. El Kadib, A.; Bousmina, M. Chitosan Bio-Based Organic-Inorganic Hybrid Aerogel Microspheres. Chemistry - A European Journal 2012, 18, 8264-8277, https://doi.org/10.1002/chem.201104006.

27. Hassabo, A.G.; Nada, A.A.; Ibrahim, H.M.; Abou-Zeid, N.Y. Impregnation of silver nanoparticles into polysaccharide substrates and their properties. Carbohydr. Polym. 2015, 122, 343-350, https://doi.org/10.1016/j.carbpol.2014.03.009.

28. Hassabo, A.; Mohamed, A. Multiamine Modified Chitosan for Removal Metal Ions from their Aqueous Solution. BioTechnology: An Indian Journal 2016, 12, 59-69.

29. Hebeish, A.; Shaarawy, S.; Hassabo, A.; El-Shafei, A. Eco-friendly multifinishing of cotton through inclusion of motmorillonite/chitosan hybrid Nanocomposite. Der Pharma Chemica 2016, 8, 259-271.

30. Chin, S.F.; Binti Romainor, A.N.; Pang, S.C. Fabrication of hydrophobic and magnetic cellulose aerogel with high oil absorption capacity. Mater. Lett. 2014, 115, 241-243, https://doi.org/10.1016/j.matlet.2013.10.061.

31. Jiao, C.; Li, T.; Wang, J.; Wang, H.; Zhang, X.; Han, X.; Du, Z.; Shang, Y.; Chen, Y. Efficient Removal of Dyes from Aqueous Solution by a Porous Sodium Alginate/gelatin/graphene Oxide Triple-network Composite Aerogel. J. Polym. Environ. 2020, 28, 1492-1502, https://doi.org/10.1007/s10924-020-01702-1.

32. Yi, Z.; Tang, Q.; Jiang, T.; Cheng, Y. Adsorption performance of hydrophobic/hydrophilic silica aerogel for low concentration organic pollutant in aqueous solution. Nanotechnology Reviews 2019, 8, 266-274, https://doi.org/10.1515/ntrev-2019-0025.

33. Olalekan, A.P.; Dada, A.O.; Adesina, O.A. Silica aerogel as a viable absorbent for oil spill remediation. Journal of Encapsulation and Adsorption Sciences 2014, 4, 122, http://dx.doi.org/10.4236/jeas.2014.44013.

34. Hu, Y.; Li, S.; Jackson, T.; Moussa, H.; Abidi, N. Preparation, Characterization, and Cationic Functionalization of Cellulose-Based Aerogels for Wastewater Clarification. Journal of Materials 2016, 2016, 3186589, https://doi.org/10.1155/2016/3186589.

35. Gregorio-Jauregui, K.M.; Pineda, M.G.; Rivera-Salinas, J.E.; Hurtado, G.; Saade, H.; Martinez, J.L.; Ilyina, A.; López, R.G. One-Step Method for Preparation of Magnetic Nanoparticles Coated with Chitosan. Journal of Nanomaterials 2012, 2012, 813958, https://doi.org/10.1155/2012/813958.

36. Reddy, D.H.K.; Lee, S.-M. Application of magnetic chitosan composites for the removal of toxic metal and dyes from aqueous solutions. Adv. Colloid Interface Sci. 2013, 201-202, 68-93, https://doi.org/10.1016/j.cis.2013.10.002. 
37. Dodi, G.; Hritcu, D.; Lisa, G.; Popa, M.I. Core-shell magnetic chitosan particles functionalized by grafting: Synthesis and characterization. Chem. Eng. J. 2012, 203, 130-141, https://doi.org/10.1016/j.cej.2012.06.133.

38. Zhang, B.; Hu, R.; Sun, D.; Wu, T.; Li, Y. Fabrication of chitosan/magnetite-graphene oxide composites as a novel bioadsorbent for adsorption and detoxification of $\mathrm{Cr}(\mathrm{VI})$ from aqueous solution. Sci. Rep. 2018, 8, 15397, https://doi.org/10.1038/s41598-018-33925-7.

39. Lu, P.; Hsieh, Y.-L. Preparation and characterization of cellulose nanocrystals from rice straw. Carbohydr. Polym. 2012, 87, 564-573, https://doi.org/10.1016/j.carbpol.2011.08.022.

40. Elwakeel, K.Z. Removal of Reactive Black 5 from aqueous solutions using magnetic chitosan resins. $J$. Hazard. Mater. 2009, 167, 383-392, https://doi.org/10.1016/j.jhazmat.2009.01.051.

41. Sahmoune, M.; Louhab, K. Kinetic analysis of trivalent chromium biosorption by dead Streptomyces rimosus biomass. Arabian Journal for Science and Engineering 2010, 35, 69-80.

42. Sahmoune, M.N.; Louhab, K.; Boukhiar, A. Biosorption of Cr (III) from Aqueous Solutions Using Bacterium Biomass Streptomyces rimosus. International Journal of Environmental Research 2009, 3, 229238, https://doi.org/10.22059/ijer.2009.50.

43. Wasewar, K.L.; Atif, M.; Prasad, B.; Mishra, I.M. Adsorption of Zinc using Tea Factory Waste: Kinetics, Equilibrium and Thermodynamics. CLEAN - Soil, Air, Water 2008, 36, 320-329, https://doi.org/10.1002/clen.200700139.

44. Sinha, P.; Datar, A.; Jeong, C.; Deng, X.; Chung, Y.G.; Lin, L.-C. Surface Area Determination of Porous Materials Using the Brunauer-Emmett-Teller (BET) Method: Limitations and Improvements. The Journal of Physical Chemistry C 2019, 123, 20195-20209, https://doi.org/10.1021/acs.jpcc.9b02116.

45. El-Zawahry, M.M.; Abdelghaffar, F.; Abdelghaffar, R.A.; Mashaly, H.M. Functionalization of the aquatic weed water hyacinth Eichhornia crassipes by using zinc oxide nanoparticles for removal of organic dyes effluent. Fibers and Polymers 2016, 17, 186-193, https://doi.org/10.1007/s12221-016-4818-3.

46. Abo-Shosha, M.H.; Nassar, F.A.; Haggag, K.M.; El-Sayed, Z.; Hassabo, A.G. Utilization of some fatty acid/peg condensates as emulsifiers in kerosene paste pigment printing. Research Journal of Textile and Apparel 2009, 13, 65.

47. Hassabo, A.G.; Mohamed, A.L.; Shaarawy, S.; Hebeish, A. Novel micro-composites based on phosphorylated biopolymer/polyethyleneimine/clay mixture for cotton multi-functionalities performance. Bioscience Research 2018, 15, 2568-2582.

48. Hassabo, A.G.; Sharaawy, S.; Mohamed, A.L. Saturated fatty acids derivatives as assistants materials for textile processes. Journal of Textile Science \& Fashion Technology 2018, 1, 000516, http://dx.doi.org/10.33552/JTSFT.2018.01.000516.

49. Aboelnaga, A.; Shaarawy, S.; Hassabo, A.G. Polyaconitic acid/functional amine/azo dye composite as a novel hyper-branched polymer for cotton fabric functionalization. Colloids Surf. B. Biointerfaces 2018, 172, 545-554, https://doi.org/10.1016/j.colsurfb.2018.09.012.

50. Hassabo AG, Sharaawy S, Mohamed AL, Unsaturated fatty acids based materials as auxiliaries for printing and finishing of cellulosic fabrics, Biointerface Research in Applied Chemistry, 2019; 9: 4284 - 4291. https://doi.org/10.33263/BRIAC95.284291.

51. Hakeim, O.A.; Haroun, A.A.; Trif, L.; Feczkó, T. Hyperbranched polyester encapsulated phthalocyanine pigments for in situ printing of cellulosic fabrics. Adv. Polym. Tech. 2018, 37, 3123-3135, https://doi.org/10.1002/adv.22083.

52. Poursaberi, T.; Hassanisadi, M. Magnetic Removal of Reactive Black 5 from Wastewater Using Ionic Liquid Grafted-Magnetic Nanoparticles. CLEAN - Soil, Air, Water 2013, 41, 1208-1215, https://doi.org/10.1002/clen.201200160.

53. Kannan, N.; Sundaram, M.M. Kinetics and mechanism of removal of methylene blue by adsorption on various carbons - a comparative study. Dyes and Pigments 2001, 51, 25-40, https://doi.org/10.1016/S01437208(01)00056-0.

54. Ho, Y.S.; Wase, D.A.J.; Forster, C.F. Kinetic Studies of Competitive Heavy Metal Adsorption by Sphagnum Moss Peat. Environ. Technol. 1996, 17, 71-77, https://doi.org/10.1080/09593331708616362.

55. Hassabo, A.G. Synthesis and deposition of functional nanomaterials on natural fibres. PhD Degree, RWTH Aachen University, Germany 2011.

56. Hassabo, A.G.; Mendrek, A.; Popescu, C.; Keul, H.; Möller, M. Deposition of Functionalized Polyethylenimine-Dye onto Cotton and Wool Fibres. Research Journal of Textile and Apparel 2014, 18, 3649, https://doi.org/10.1108/RJTA-18-01-2014-B006.

57. Wang, S.; Boyjoo, Y.; Choueib, A.; Zhu, Z.H. Removal of dyes from aqueous solution using fly ash and red mud. Water Res. 2005, 39, 129-138, https://doi.org/10.1016/j.watres.2004.09.011.

58. Ardejani, F.D.; Badii, K.; Limaee, N.Y.; Shafaei, S.Z.; Mirhabibi, A.R. Adsorption of Direct Red 80 dye from aqueous solution onto almond shells: Effect of $\mathrm{pH}$, initial concentration and shell type. J. Hazard. Mater. 2008, 151, 730-737, https://doi.org/10.1016/j.jhazmat.2007.06.048.

59. Kim, U.-J.; Kuga, S.; Wada, M.; Okano, T.; Kondo, T. Periodate Oxidation of Crystalline Cellulose. Biomacromolecules 2000, 1, 488-492, https://doi.org/10.1021/bm0000337. 
60. Kitkulnumchai, Y.; Ajavakom, A.; Sukwattanasinitt, M. Treatment of oxidized cellulose fabric with chitosan and its surface activity towards anionic reactive dyes. Cellulose 2008, 15, 599-608, https://doi.org/10.1007/s10570-008-9214-8.

61. Li, Z.; Shao, L.; Hu, W.; Zheng, T.; Lu, L.; Cao, Y.; Chen, Y. Excellent reusable chitosan/cellulose aerogel as an oil and organic solvent absorbent. Carbohydr. Polym. 2018, 191, 183-190, https://doi.org/10.1016/j.carbpol.2018.03.027.

62. Hakeim, O.A.; El-Zawahry, M.; Aly, N.M.; El-Hawary, N.S.; Diab, H.A.; Ali Marwa, A. Anti-static and functional properties of asminosilsesquioxane oligomer treated and dyed fabrics. J. Text. Assoc. 2015, 76, 90-101.

63. Judai, K.; Iguchi, N.; Hatakeyama, Y. Low-Temperature Production of Genuinely Amorphous Carbon from Highly Reactive Nanoacetylide Precursors. Journal of Chemistry 2016, 2016, 7840687, https://doi.org/10.1155/2016/7840687.

64. Mandal, A.; Chakrabarty, D. Isolation of nanocellulose from waste sugarcane bagasse (SCB) and its characterization. Carbohydr. Polym. 2011, 86, 1291-1299, https://doi.org/10.1016/j.carbpol.2011.06.030.

65. Habibi, Y.; Lucia, L.A.; Rojas, O.J. Cellulose Nanocrystals: Chemistry, Self-Assembly, and Applications. Chem. Rev. 2010, 110, 3479-3500, https://doi.org/10.1021/cr900339w.

66. Li, J.; Wei, X.; Wang, Q.; Chen, J.; Chang, G.; Kong, L.; Su, J.; Liu, Y. Homogeneous isolation of nanocellulose from sugarcane bagasse by high pressure homogenization. Carbohydr. Polym. 2012, 90, 16091613, https://doi.org/10.1016/j.carbpol.2012.07.038.

67. Zhao, W.; Zhu, J.; Wei, W.; Ma, L.; Zhu, J.; Xie, J. Comparative study of modified/non-modified aluminum and silica aerogels for anionic dye adsorption performance. RSC Advances 2018, 8, 29129-29140, https://doi.org/10.1039/C8RA05532G.

68. Gu, H.; Zhou, X.; Lyu, S.; Pan, D.; Dong, M.; Wu, S.; Ding, T.; Wei, X.; Seok, I.; Wei, S.; Guo, Z. Magnetic nanocellulose-magnetite aerogel for easy oil adsorption. J. Colloid Interface Sci. 2020, 560, 849-856, https://doi.org/10.1016/j.jcis.2019.10.084.

69. Zhu, H.Y.; Jiang, R.; Xiao, L.; Zeng, G.M. Preparation, characterization, adsorption kinetics and thermodynamics of novel magnetic chitosan enwrapping nanosized $\gamma$-Fe2O3 and multi-walled carbon nanotubes with enhanced adsorption properties for methyl orange. Bioresour. Technol. 2010, 101, 50635069, https://doi.org/10.1016/j.biortech.2010.01.107.

70. Wang, Y.; Wang, H.; Peng, H.; Wang, Z.; Wu, J.; Liu, Z. Dye Adsorption from Aqueous Solution by Cellulose/Chitosan Composite: Equilibrium, Kinetics, and Thermodynamics. Fibers and Polymers 2018, 19, 340-349, https://doi.org/10.1007/s12221-018-7520-9.

71. Suresh Kumar, P.; Korving, L.; Keesman, K.J.; van Loosdrecht, M.C.M.; Witkamp, G.-J. Effect of pore size distribution and particle size of porous metal oxides on phosphate adsorption capacity and kinetics. Chem. Eng. J. 2019, 358, 160-169, https://doi.org/10.1016/j.cej.2018.09.202.

72. Hameed, B.H.; Mahmoud, D.K.; Ahmad, A.L. Equilibrium modeling and kinetic studies on the adsorption of basic dye by a low-cost adsorbent: Coconut (Cocos nucifera) bunch waste. J. Hazard. Mater. 2008, 158, 65-72, https://doi.org/10.1016/j.jhazmat.2008.01.034.

73. Gopinathan, R.; Bhowal, A.; Garlapati, C. Adsorption Studies of Some Anionic Dyes Adsorbed by Chitosan and New Four-Parameter Adsorption Isotherm Model. J. Chem. Eng. Data 2019, 64, 2320-2328, https://doi.org/10.1021/acs.jced.8b01102.

74. Chatterjee, S.; Lee, M.W.; Woo, S.H. Adsorption of congo red by chitosan hydrogel beads impregnated with carbon nanotubes. Bioresour. Technol. 2010, 101, 1800-1806, https://doi.org/10.1016/j.biortech.2009.10.051.

75. Du, Q.; Sun, J.; Li, Y.; Yang, X.; Wang, X.; Wang, Z.; Xia, L. Highly enhanced adsorption of congo red onto graphene oxide/chitosan fibers by wet-chemical etching off silica nanoparticles. Chem. Eng. J. 2014, 245, 99-106, https://doi.org/10.1016/j.cej.2014.02.006.

76. Wang, J.; Zhou, Q.; Song, D.; Qi, B.; Zhang, Y.; Shao, Y.; Shao, Z. Chitosan-silica composite aerogels: preparation, characterization and Congo red adsorption. J. Sol-Gel Sci. Technol. 2015, 76, 501-509, https://doi.org/10.1007/s10971-015-3800-7.

77. Wang, L.; Wang, A. Adsorption characteristics of Congo Red onto the chitosan/montmorillonite nanocomposite. J. Hazard. Mater. 2007, 147, 979-985, https://doi.org/10.1016/j.jhazmat.2007.01.145. 